\title{
Domestic road infrastructure and international trade: Evidence from Turkey
}

\author{
A. Kerem Coşar ${ }^{\mathrm{a}, *}$, Banu Demir ${ }^{\mathrm{b}}$ \\ a Stockholm School of Economics, Department of Economics, Sweden \\ ${ }^{\mathrm{b}}$ Bilkent University, Department of Economics, Turkey
}

\section{A R T I C L E I N F O}

\section{Article history:}

Received 22 January 2015

Received in revised form 16 September 2015

Accepted 3 October 2015

Available online 22 October 2015

\section{Keywords:}

International trade

Market access

Transportation infrastructure

Time-sensitive industries

\begin{abstract}
A B S T R A C T
Drawing on the large-scale public investment in roads undertaken in Turkey during the 2000s, this paper contributes to our understanding of how internal transportation infrastructure affects regional access to international markets. Using data on international trade of Turkish provinces and the change in the capacity of the roads connecting them to the international gateways of the country, we estimate the distance elasticity of trade associated with roads of varying capacity. Three key results emerge. First, the cost of an average shipment over a highcapacity expressway is about 70\% lower than it is over single-lane roads. Second, the present value of a 10-year stream of trade flows generated by a one-dollar investment in road infrastructure ranges between $\$ 0.7$ and $\$ 2$. Third, the reduction in transportation costs is greater the more transportation-sensitive an industry is. To the extent that efficient logistics enable countries to take part in global supply chains and exploit their comparative advantages, our findings have important developmental implications.
\end{abstract}

(C) 2015 Elsevier B.V. All rights reserved.

\section{Introduction}

Poor domestic transportation infrastructure in developing countries is often cited as an important impediment for accessing international markets. Yet, evidence on how a major improvement in the transport network of a country affects the volume and composition of its international trade is scarce. We fill this gap by estimating the impact of a recent large-scale public investment in Turkey aimed at improving the quality of the road network. Our main finding is that, by reducing the cost of shipping, high-capacity expressways improved the foreign market access of regions remote from the ports.

A typical international shipment involves both domestic and international transportation with a possible transhipment across different modes at a harbor, an airport, or a border crossing. Quantitative models of international trade rarely distinguish these separate segments. Bilateral distances used in the estimation of gravity equation are typically the distances between the main cities of countries. While measures taking into account internal distances are available (Redding and Venables, 2004), they do not explicitly control for the quality of transportation

\footnotetext{
خ For their comments and constructive suggestions, we thank our discussants, Costas Arkolakis, Asena Caner, Anca Cristea, and Dave Donaldson, as well as Kjell G. Salvanes, the editor, two anonymous referees, and numerous seminar participants.

* Corresponding author.

E-mail addresses: kerem.cosar@gmail.com (A.K. Coșar), banup@bilkent.edu.tr (B. Demir).
}

infrastructure which is clearly important in determining domestic freight costs besides distance.

Intuition and evidence suggest that the domestic component may account for a nonnegligible part of the overall cost of shipping goods across borders. Decomposing the ad valorem tax equivalent of trade costs between industrialized countries, Anderson and van Wincoop (2004) estimate that domestic distribution costs are more than twice as high as international transportation costs ( 55 versus $21 \%$, respectively). Rousslang and To (1993) document that domestic freight costs on US imports are in the same order of magnitude as international freight costs. Using data on the cost of shipping a standard container from Baltimore to 64 destination cities around the world, Limao and Venables (2001)find that the per unit distance cost in the overland segment of the journey is significantly higher than in the sea leg. Moreover, these costs critically depend on the quality of the transportation infrastructure. Atkin and Donaldson (2014) estimate that intranational trade costs in Ethiopia and Nigeria are 4 to 5 times larger than the estimates obtained for the United States. Consistent with this evidence, recent policy initiatives emphasize that an inadequate transportation infrastructure and inefficient logistics sector can severely impede developing countries' competitiveness (ADBI, 2009; WB, 2009; WTO, 2004). For instance, the World Bank cites trade facilitation, which incorporates domestic transportation, as its "largest and most rapidly increasing trade-related work" as of 2013. Thus, quantifying the effect of internal transportation costs on international trade and understanding its channels are important for assessing trade-related benefits of transportation infrastructure investments. 
As a case in point, Turkey increased the share of four-lane expressways in its interprovincial road stock from 11 to 35\% between 2003 and 2012. The expansion of existing two-lane roads into divided fourlane expressways significantly improved the quality and capacity of roads while the total length remained essentially unchanged. Important for our study, these investments affected regions differently depending on where they were made, improving the connectivity of some regions to the international trade gateways of the country more than others. To exploit this variation, we use a rich dataset that provides information on province-level trade disaggregated by the international gateways of the country and estimate that the investment under study significantly reduced transport costs, and thus increased regional exports and imports. Using our baseline estimate, we calculate the cost of shipping over the mean distance in our data. Accordingly, the cost of an average-distance shipment drops by about $70 \%$ if the complete route is upgraded from a single carriageway to expressway. This result is robust to alternative specifications and instrumenting the change in route-specific road capacity with the initial capacity. Our estimates imply that the present value of a 10-year stream of trade flows generated by a one-dollar investment in road infrastructure ranges between \$0.7 and \$2. Finally, we show that transportation-intensive industries displayed higher trade growth in regions with above-average improvements in connectivity. This constitutes a plausible channel for the aggregate response of regional trade and strengthens our identification.

Recent work highlights the prevalence and importance of the issues that we explore. As noted above, Atkin and Donaldson (2014) estimate large internal trade costs in Ethiopia and Nigeria. Coşar and Fajgelbaum (forthcoming) develop a model in which these costs lead to regional specialization in export-oriented industries close to ports, and verify this prediction in China. Allen and Arkolakis (2014) incorporate realistic topographical features of geography into a spatial model of trade and estimate the rate of return to the US Interstate Highway System. Focusing on historical episodes, Donaldson (2012) and Donaldson and Hornbeck (2013) analyze the welfare gains from railroads in India and the United States, respectively. We complement these studies by providing evidence on how a large-scale, capacity-enhancing public investment in transportation infrastructure in a developing country affects the volume and composition of its regions' international trade.

Our paper also contributes to a strand of literature that focuses on estimating the effect of transport infrastructure on trade and sectoral productivity. Using cross-country data, Limao and Venables (2001) and Yeaple and Golub (2007) find that infrastructure is an important determinant of trade costs, bilateral trade volumes, and comparative advantage. ${ }^{1}$ Volpe Martincus and Blyde (2013) use the 2010 Chilean earthquake as a natural experiment to estimate the response of firmlevel exports to the resulting geographical variation in access to ports. Volpe Martincus et al. (2013) use historical routes in Peru to instrument for the location of new roads and find a sizeable impact on firm-level exports. A recent report by IADB (2013) explores the importance of domestic transportation infrastructure for regional exports in a number of Latin American countries. Albarran et al. (2013) find a positive impact of improved transportation infrastructure on small and medium-sized firms' probability of exporting in Spain. We complement these studies by proposing an alternative measure of road quality and an identification strategy for estimating its effect on trade. We also explore the importance of alternative channels through which transportation infrastructure could exert its effects. To the extent that reducing internal

\footnotetext{
${ }^{1}$ Besides the length of roads, paved roads, and railways per sq km of country area, the infrastructure index used by Limao and Venables (2001) contains telephone main lines per person as well, making it impossible to tease out the isolated effect of the transportation infrastructure. In contrast, Yeaple and Golub (2007) investigate roads, telecom, and power infrastructure separately and find roads to have the biggest effect.
}

transport costs helps developing countries participate in global supply chains in transportation-intensive industries, our results have important implications for industrial and commercial policies.

The next section introduces the background and the data. The results are presented in Section 3.

\section{Data and preliminary analysis}

\subsection{Background}

Turkey is an upper-middle-income country (according to the World Bank classification) with a large population (78 million as of 2014) and a diversified economy. The country is the world's 17th-largest economy, 22th-largest exporter and 13th-largest importer of merchandise goods by value (World Trade Report 2014, excluding intra-EU28 trade). It has been in a customs union for manufactured goods with the European Union since 1996, which accounts for more than half of the country's trade. Turkey is the fifth-largest exporter to the European Union and its seventh-largest importer.

Administratively, the country is divided into 81 contiguous provinces (il in Turkish) of varying geographic and economic size. ${ }^{2}$ Each province is further composed of districts (ilçe). Some of these districts jointly form the provincial center (il merkezi), which is typically the largest concentration of urban population in a province. The top map in Fig. 1 outlines provincial boundaries and centers (see the notes to the figure).

Road transport is the primary mode of freight transport in Turkey. It accounts for about $90 \%$ of domestic freight (by tonne-km) and passenger traffic. ${ }^{3}$ While the interprovincial road network has been extensive and paved, its capacity was considered quite inadequate until recently. In order to relieve the congestion and reduce the high rate of road accidents, the authorities launched a large-scale public investment in 2002 in order to expand existing single carriageways (i.e., two-lane undivided roads) into dual carriageways (i.e., divided four-lane expressways). The investment was centrally planned and financed from the central government's budget with no direct involvement of local administrations.

As a result, the length of dual carriageways increased by more than threefold during the 2003-2012 period, while total road stock remained essentially unchanged (middle and bottom maps in Figs. 1 and 2). This capacity-expansion feature of the investment distinguishes the episode under study from the construction of new roads or the pavement of existing dirt roads, settings on which the related literature typically focuses (IADB, 2013).

External evidence suggests that the upgrades improved road transport quality in Turkey. Since 2007, the World Bank has been conducting a worldwide survey among logistics professionals every two years. The results are aggregated into the Logistics Performance Index (LPI), which ranges between 0 and 5; a higher LPI value indicates a more developed transportation sector as perceived by industry experts. In 2007, Turkey's score was 2.94, lower than the OECD average of 3.61. In 2012, Turkey's LPI value of 3.62 almost caught up with the OECD average of 3.68. Broken down into its components, the LPI covers the following six areas: customs, infrastructure, logistics competence, tracking and tracing, international shipments, and timeliness. In 2007, Turkey ranked 39th among 150 countries for the quality of trade- and transport-related infrastructure and 52nd for the timeliness of domestic shipments in reaching the destination. In 2012, Turkey scored higher on both indices; the country moved up 14 places in the infrastructure ranking, and 25 places in the timeliness ranking. On other indices, Turkey's rankings

\footnotetext{
2 Provinces correspond to the NUTS 3 (Nomenclature of Territorial Units for Statistics) level in the Eurostat classification of regions.

${ }^{3}$ See page 7 in GDH (2012). Data on modal shares by value are not available.
} 


\section{Provincial Boundaries and Centers}

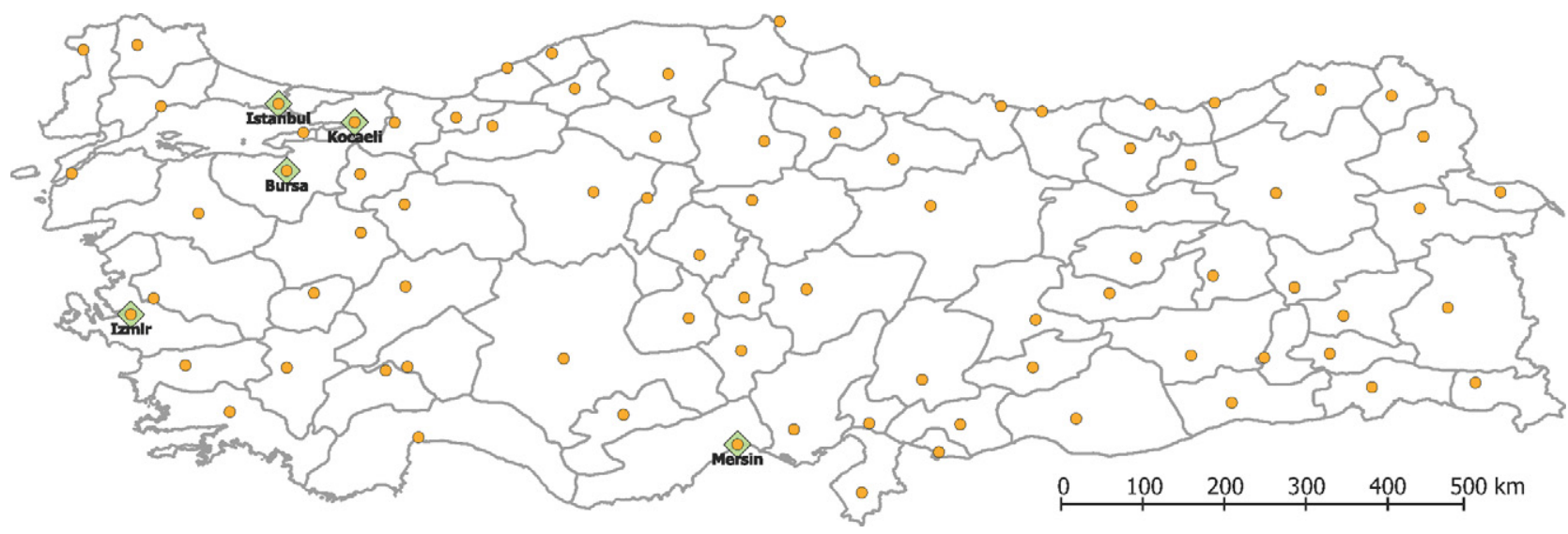

Road network in 2002

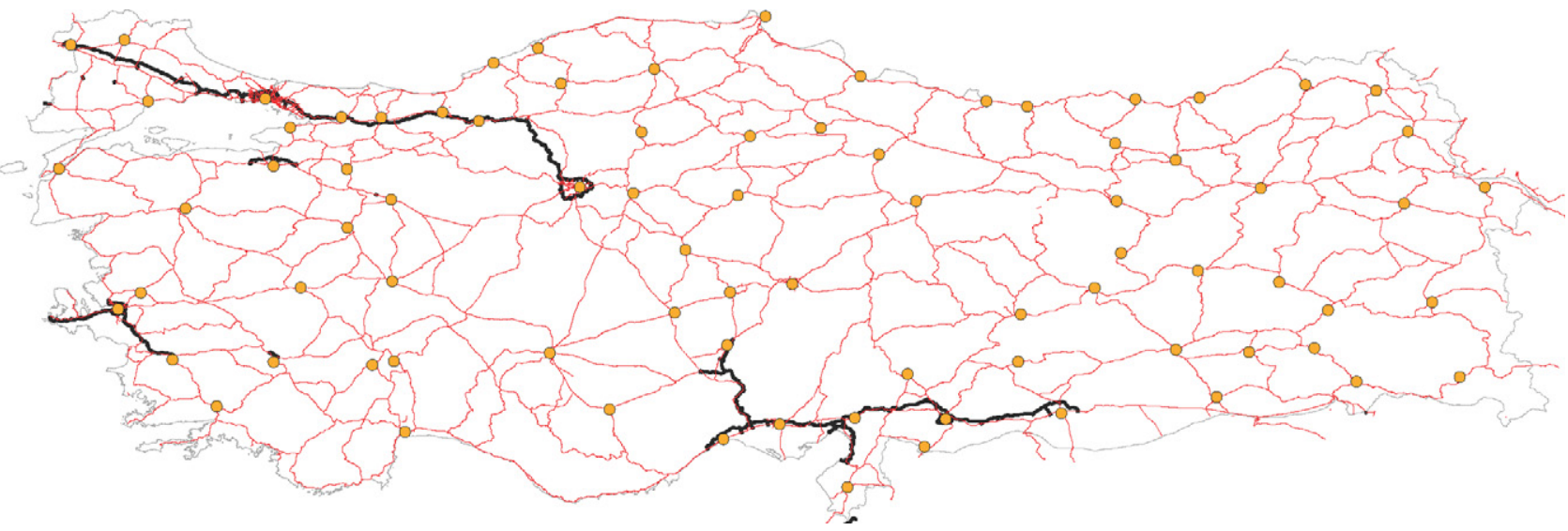

Road network in 2012

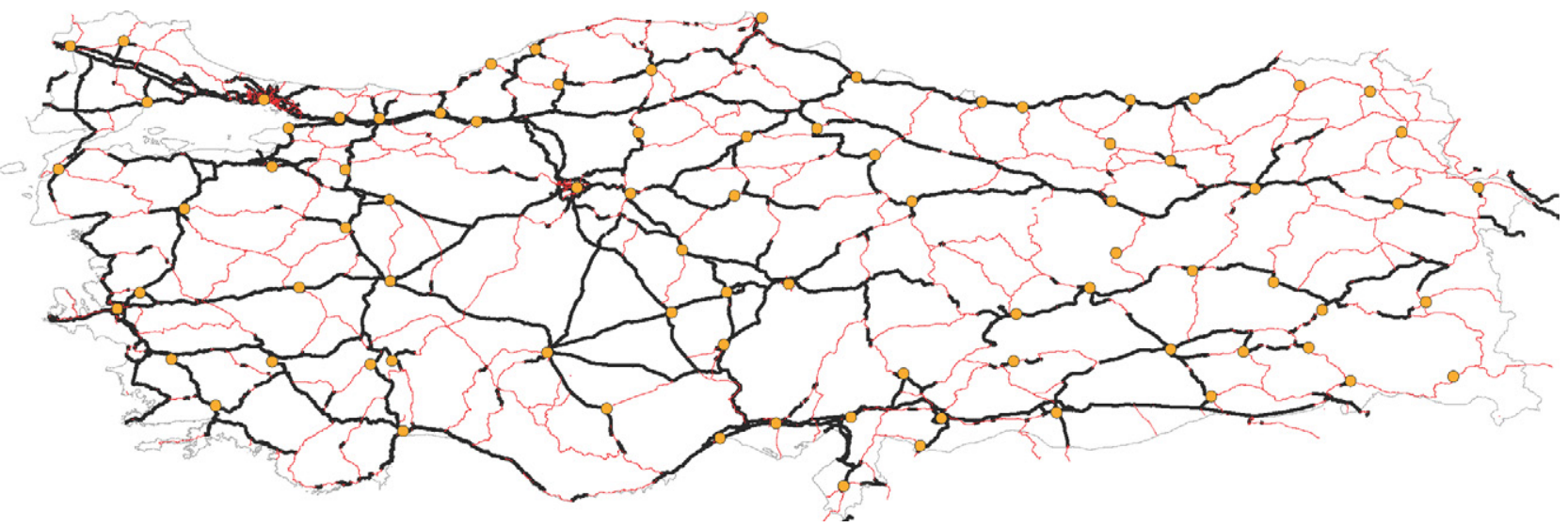

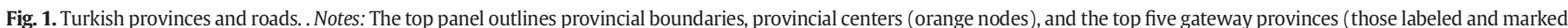

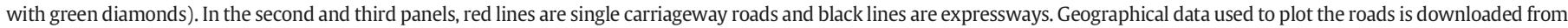
http://www.diva-gis.org.

have not changed significantly: the country moved up one place in the customs ranking, four places in the logistics competence ranking, and five places in the tracking and tracing ranking. Consistent with reductions in shipping costs, Turkey's ranking in the international shipments index, which measures the ease of arranging competitively priced shipments, has also improved: the country moved up 11 places between 2007 and 2012. Furthermore, according to the Global Competitiveness Report (World Economic Forum) rankings based on the quality of 


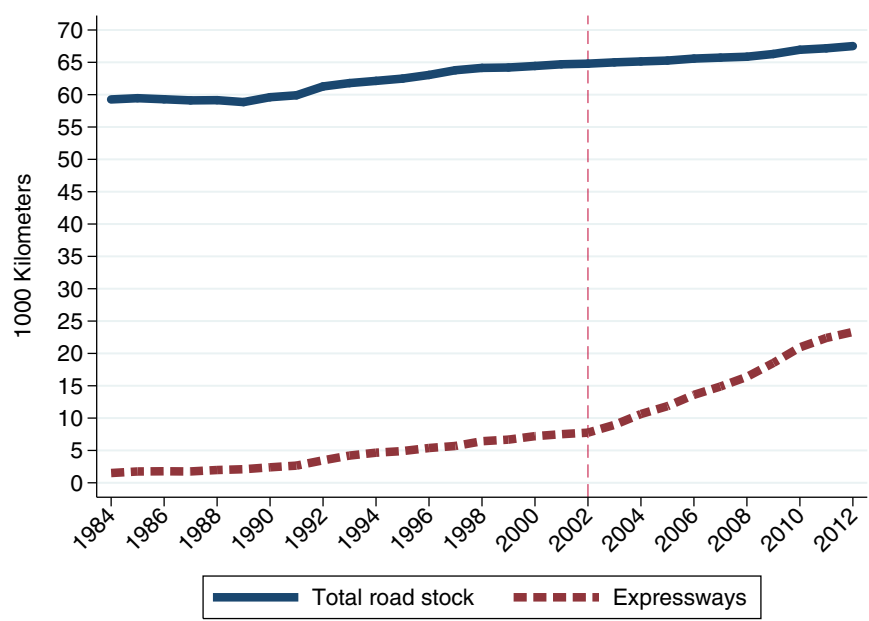

Fig. 2. Roads over time. Notes: This figure plots total length of intercity roads and expressways between 1984-2002. The y-axis in thousand kilometers.

road infrastructure, Turkey moved up 10 places to 43th among 148 countries between 2006-2012. ${ }^{4}$

We finish this subsection by noting that the objectives of the investment program alleviate concerns related to the selection of provinces for foreign trade-related outcomes. Policy documents explicitly state that the goal was "to ensure the integrity of the national network and address capacity constraints that lead to road traffic accidents." (GDH, 2014). The long-term goal is to improve connections between all provincial centers to form a comprehensive grid network spanning the country, rather than boosting the international trade from particular regions. Against this backdrop, we will further address endogeneity concerns in our empirical investigation.

\subsection{Data}

Data on province-level manufacturing exports and imports for the 2003-2012 period are provided by the Turkish Statistical Institute (TUIK). An important aspect of these flows for our purposes is the gateway $g$ through which trade occurs. 20 out of 81 provinces are gateway provinces, hosting either a seaport or a border crossing. We observe annual trade flows between each province-gateway pair: trade $e_{p g t}^{f}$ denotes export or import flow $f=\{\exp , i m p\}$ of province $p$ through gateway $g$ at year $t$, denominated in current year USD.

Trade flows are further disaggregated by partner country and 22 manufacturing industries (in 2 digit ISIC Rev.3 classification). For confidentiality reasons, TUIK does not disclose the data at the provincegateway-country-industry-year (pgcit) level since individual firms may be detected at this level of detail. We thus work with trade data at the province-gateway-year (pgt), province-gateway-country-year (pgct) and province-gateway-industry-year (pgit) levels, depending on the specification.

Table 1 summarizes key descriptive trade statistics. As the top panel shows, exports and imports both increased substantially between 2003 and 2012, regardless of the unit of observation. The

\footnotetext{
4 The ranking is constructed based on a survey question that asks respondents to rate the quality of roads in their countries from 1 ("extremely underdeveloped") to 7 ("extensive and efficient-among the best in the world"). Turkey improved its score from 3.72 in 2006-2007 to 4.87 in 2012-2013. Demir (2011) also uses quality indices published by the World Economic Forum and reports that the elasticity of Turkey's trade with respect to the quality of its overall transport infrastructure is around unity.
}

Table 1

Summary statistics.

\begin{tabular}{|c|c|c|c|c|c|c|}
\hline \multicolumn{7}{|c|}{ Trade statistics (in 1000 USD) } \\
\hline & \multicolumn{2}{|c|}{ pg sample } & \multicolumn{2}{|c|}{ pgc sample } & \multicolumn{2}{|c|}{ pgi sample } \\
\hline & Mean & Std & Mean & Std & Mean & Std \\
\hline$\Delta \ln ($ exports) & 1.692 & 2.111 & 1.478 & 2.182 & 1.790 & 2.484 \\
\hline$\Delta \ln$ (imports) & 1.486 & 2.169 & 1.168 & 2.423 & 1.361 & 2.359 \\
\hline
\end{tabular}

Extensive margins of trade (per province \#)

\begin{tabular}{|c|c|c|c|c|}
\hline & \multicolumn{2}{|l|}{2003} & \multicolumn{2}{|l|}{2012} \\
\hline & Mean & Std & Mean & Std \\
\hline Gateways, exports & 7.519 & 4.051 & 12.188 & 4.537 \\
\hline Gateways, imports & 7.163 & 3.354 & 9.247 & 3.727 \\
\hline Countries, exports & 72.739 & 46.644 & 105.658 & 48.821 \\
\hline Countries, imports & 55.088 & 36.570 & 73.169 & 42.685 \\
\hline Industries, exports & 17.164 & 5.580 & 19.911 & 4.305 \\
\hline Industries, imports & 17.295 & 5.695 & 19.647 & 4.489 \\
\hline Distance (km, across pg pairs) & 820 & 422 & & \\
\hline Expressway share (\%, across pg pairs) & 9.1 & 3.1 & 31.1 & 4.1 \\
\hline
\end{tabular}

middle panel shows the extensive margins of this increase. The number of gateways through which provinces trade, the number of countries they trade with and the number of industries they trade in all display sizable increases from 2003 to 2012. These patterns suggest that the expansion of road capacity between 2003-2012 may have affected regional trade on extensive as well as intensive margins. $^{5}$

Data on the stock and composition of roads at the province level are provided by the Turkish General Directorate of Highways. To be precise, our data inform us about the total length of all roads $\left(\right.$ roadStock $_{p t}$ ) and expressways (expressway ${ }_{p t}$ ) within provincial boundaries at each year between 2003-2012. By definition, expressway $_{p t} \leq$ roadStock $_{p t}$, which holds with strict inequality for all province-year observations.

Several remarks are in order. The road data are available at a level of aggregation that does not inform us about particular segments between nodes. Neither do we have geographical information about the network. Fig. 3 helps to illustrate this. The three tiles here represent three provinces, their centers and boundaries. At any given year, the network is composed of single carriage roads (red lines) and expressways (black lines). We only know the total length of these roads within provincial boundaries, rather than whether there is an expressway connecting the centers $\left(P_{1}, P_{2}, G\right)$. Since trade data come at the same level of aggregation, with exporters/importers spread within provinces' boundaries, the lack of geographical detail on roads does not strike us as critical.

For our empirical analysis, however, we need a measure of provincial access to gateways. We obtained shortest road distances dist $t_{p g}$ and the associated routes $J_{p g}$ between provincial centers from Google Maps. $J_{p g}$ is the set of provinces one has to traverse on the shortest distance route between $p$ and $g$, including the origin and the destination. In Fig. 3, $J_{P_{1}, G}=\left(P_{1}, P_{2}, G\right)$ and dist $t_{P_{1}, G}$ is the length of the road connecting $P_{1}$ and $G$ through $P_{2}$.

\footnotetext{
${ }^{5}$ Since our empirical analysis will exploit trade flows at the province-gateway level, it is important to note that it is not just the nearest gateway that matters for a province's foreign trade. Ports and border crossings are specialized in industries and trade partners: an overwhelming majority of trade in a certain industry with a certain country goes through a single port. This specialization is consistent with both geography-the border crossing to Syria is irrelevant for trade with Germany-and logistics technology-there are strong increasing returns at ports due to containerization and industry-specific port equipment. With this in mind, it is important to consider all existing or newly formed pg links during our data period.
} 


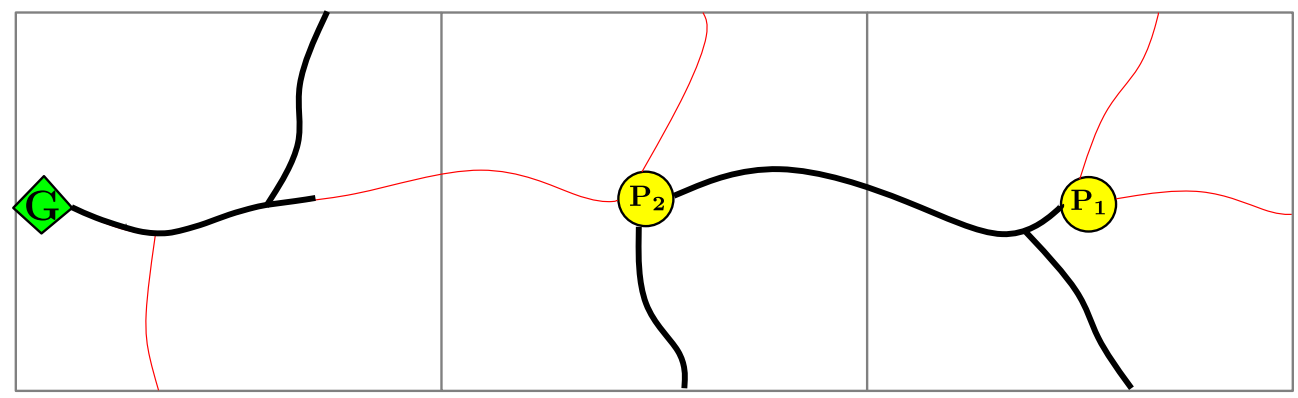

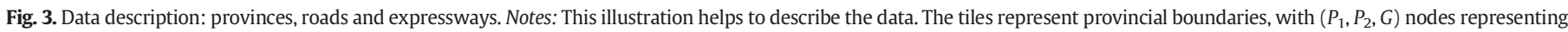
provincial centers. $G$ stands for gateway. Red (thin) lines are single carriage roads and black (thick) lines are dual carriage expressways. See text for details.

In order to calculate $p g$-level improvements in road capacity over time, we calculate the expressway road share on the shortest distance route $J_{p g}$ at year $t:^{6}$

$\operatorname{ers}_{p g t}=\frac{\sum_{j \in J_{p g}} \text { expressway }_{j t}}{\sum_{j \in J_{p g}} \text { roadStock }_{j, 2003}}$.

The bottom panel of Table 1 shows summary statistics for this variable over time (an increase from $9.1 \%$ in 2003 to $31.1 \%$ in 2012), as well as for time invariant $p g$ distances.

In what follows, we propose to identify the effect of road capacity on trade through the period change in expressway road share:

$\Delta e r s_{p g}=e r s_{p g, 2012}-e r s_{p g, 2003}$,

which shows considerable variation without clustering in certain regions of the country (Fig. 4) and suggests that province-gateway pairs with poor initial connections experienced larger improvements (Fig. 5).

\subsection{Preliminary analysis}

Before moving on to the main empirical analysis, we note that for the purpose of estimating the transport-cost reducing impact of expressways, it would have been ideal to also have data on domestic trade between cities. Such information, however, is typically not available for developing countries. Observing the domestic components of export/ import shipments thus provides us with limited but useful information to estimate how such flows are generally affected by transport infrastructure. With 20 gateway provinces as "origins" of imports to 81 provinces and as "destinations" of exports from provinces, our data can be fit with a simple gravity model, which is a standard tool for explaining bilateral trade flows:

$\ln \operatorname{trade}_{p g}^{f}=\delta_{p}^{f}+\delta_{g}^{f}+\gamma \ln \operatorname{dist}_{p g}+\epsilon_{p g}$,

where $\left(\delta_{p}^{f}, \delta_{g}^{f}\right)$ are gateway- and province-flow fixed effects, reminiscent of exporter and importer fixed effects in international gravity estimations.

Table 2 reports the results. We estimate the distance elasticity of flows separately at the beginning (2003/04) and at the end (2011/12) of the period under consideration. Excluding own-shipments for $p=g$ with dist $=0$, i.e. exports and imports of gateway provinces through their own ports, there are 3, 200 possible flows in our data $(=81 \times 20 \times 2-20 \times 2)$. The OLS estimates in the first two

\footnotetext{
${ }^{6}$ We fix the denominator, the length of total road stock, in its 2003 value. Additions to the road network are quantitatively small over this time period (see Fig. 2), and more importantly, all upgrades were done on single carriageways that were in operation as of 2003. For the same reason, and also because we do not have access to previous years' maps, we use the shortest distance route $J_{p g}$ as obtained from Google Maps in 2013 for the entire data period. The results are robust to using yearly values for the denominator, which shows slight variation.
}

columns use positive flows only. The much higher number of observations in the 2011/12 sample is a manifestation of the extensive margin increase documented in Table 1.

Given the pervasiveness of zero flows and the well-known problems associated with using OLS to estimate gravity models (Santos-Silva and Tenreyro, 2006), we also use a Poisson pseudo-maximum likelihood (PPML) estimator in third and fourth columns. ${ }^{7}$ Consistent with the well-documented pattern in the literature, our PPML estimates of distance elasticity are smaller in absolute value than the respective OLS estimates. The estimates are in the range of elasticities reported by Head and Mayer (2014). Comparing the 2003/04 and 2011/12 sample, we see that the elasticity estimated for the latter period is smaller in absolute value: a one percent increase in distance decreases trade by 1.4 and $1.2 \%$ in the beginning versus the end of the period, respectively.

This drop motivates us to further investigate the relationship between road capacity improvements and changes in trade outcomes over time. To this end, Fig. 6 plots the residual period change in trade for provinces against a proxy that captures their improvement in accessing foreign markets. In particular, we sum export and import flows trade $_{p g}=\Sigma_{f}$ trade $f$ ) ), and fix the initial share of each gateway in a province's trade $\left(\pi_{p g}=\right.$ trade $_{p g} / \Sigma_{g}$ trade $\left.e_{p g}\right)$. We then regress $\Delta \ln$ trade $_{p g}$ on province and gateway fixed effects, and plot in the $y$ axis the average residuals using $\pi_{p g}$ as weights. This captures the average period change in trade for a province, after adjusting for its own average and the average of the gateways it trades through. The $x$-axis is simply $\Sigma_{g} \pi_{p g} \Delta e r s_{p g}$, i.e., the average improvement in a province's access to its gateways, using the same trade shares as weights. The slope of the regression line plotted in the figure is 2.997 with a p-value of 0.6 . The following section provides a more thorough examination using a rich set of controls and an instrument for road capacity expansions.

\section{Empirical analysis}

To derive our estimating equation, we specify bilateral trade flows between province $p$ and gateway $g$ in a general gravity setting:

trade $_{p g t}^{f}=\omega_{p t}^{f} \cdot \omega_{g t}^{f} \cdot T C_{p g t}^{-\theta}$,

where $\omega_{p t}^{f}$ captures time-varying province-level variables that affect its exports/imports, and $\omega_{g t}^{f}$ captures time-varying factors that affect international demand and supply through gate $g$ (such as income in destination countries that can be reached through $g$ ). $T C_{p g t}$ is the cost of transportation and $\theta>0$ denotes the elasticity of trade flows with respect to transportation costs. ${ }^{8}$

\footnotetext{
${ }^{7}$ Number of observations in these columns falls short of 3200 because the PPML routine drops exporters (importer) with no positive trade flows with any partner in the presence of exporter (importer) fixed effects.

${ }^{8}$ Since our motivation is to estimate transportation costs, we start directly with a general gravity equation and do not take a stand on the underlying source of trade. As summarized by Head and Mayer (2014), various workhorse models of trade comply with this general gravity specification while the structural interpretation of the trade elasticity $\theta$ varies across models (Arkolakis et al., 2012).
} 


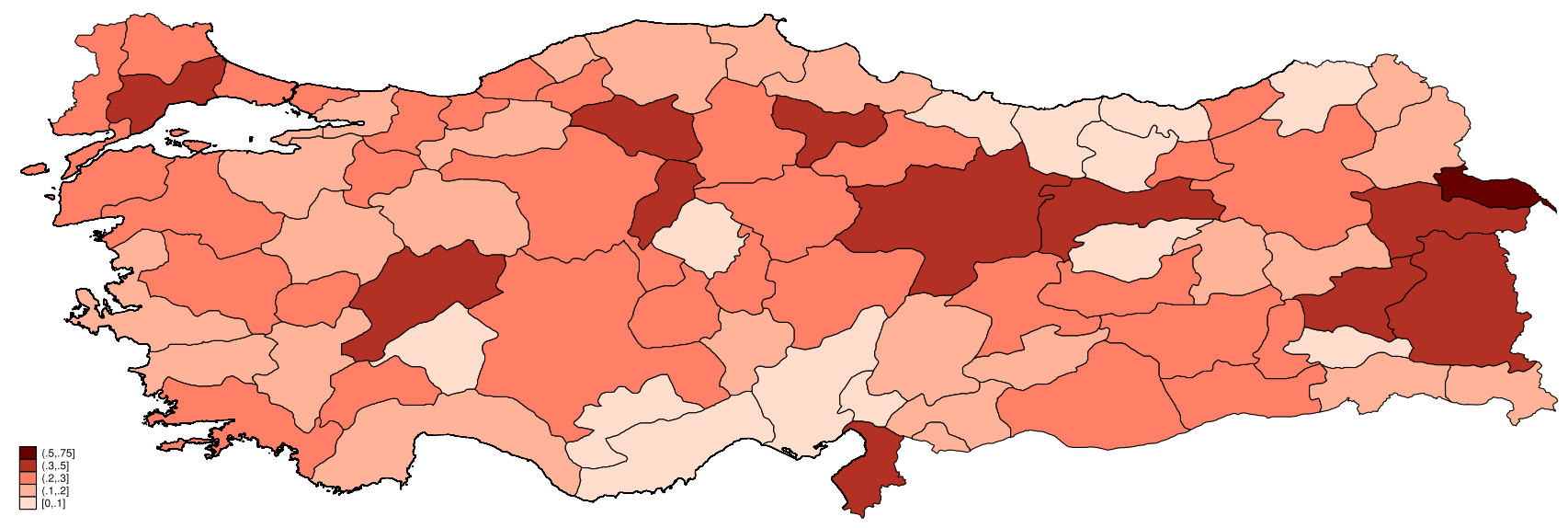

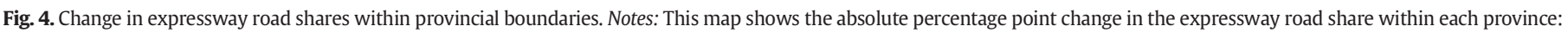
$\left(\operatorname{expressway}_{p, 2012}\right) /\left(\right.$ roadStock $\left._{p, 2003}\right)-\left(\right.$ expressway $\left._{p, 2003}\right) /\left(\right.$ roadStock $\left._{p, 2003}\right)$.

We assume that the cost of transportation at time $t$ is a function of the distance and the quality of roads connecting the $p g$ pair:

$T C_{p g t}=\operatorname{dist}_{p g}^{\tau_{e} \cdot e r s_{p g t}+\tau_{s} \cdot\left(1-e r s_{p g t}\right)}$,

where $\tau_{e}, \tau_{s}$ are positive distance elasticities associated with new expressways and old single-carriageway roads, respectively. Taking the logarithm of Eq. (3) and defining $\tau=\tau_{s}-\tau_{e}$,

$\ln T C_{p g t}=\tau\left(1-e r s_{p g t}\right) \ln \operatorname{dist}_{p g}+\tau_{e} \ln \operatorname{dist}_{p g}$.

In our setting, time-variation in transport costs is driven by changes in ers $_{p g t}$ over time, captured by the first term. We obtain the following specification by taking the logarithm of both sides in Eq. (2) and replacing $\ln T C_{p g t}$ with Eq. (4):

$\ln$ trade $_{p g t}^{f}=\ln \omega_{p t}^{f}+\ln \omega_{g t}^{f}-\theta \tau\left(1-e r s_{p g t}\right) \ln d i s t_{p g}-\theta \tau_{e} \ln d i s t_{p g} .(5)$

To gauge the long-term effect of increasing ers ${ }_{p g t}$ on trade flows, we take the time difference as

$\Delta \ln \operatorname{trade}_{p g}^{f}=\Delta \ln \omega_{p}^{f}+\Delta \ln \omega_{g}^{f}-\theta \cdot \underbrace{\tau\left[\Delta\left(1-e r s_{p g}\right)\right] \ln \operatorname{dist}_{p g}}_{=\Delta \ln T C_{p g}}$,

where $\Delta x=x_{2012}-x_{2003}$ denotes the difference between 2012 and 2003 levels of a variable. Note that the time-invariant term $\tau_{e} \ln$ dist $_{p g}$ in transport costs (5) drops when taking the difference. If the cost of transport on expressways increases with distance at a smaller rate than it does on single carriageways, i.e., if $\tau_{s}>\tau_{e} \Rightarrow \tau>0$, an increase in ers will reduce $T C$ and increase trade in Eq. (6). We are now ready to test this relationship.

\subsection{Road capacity and trade}

Replacing $\Delta\left(1-e r s_{p g}\right)=-\Delta e r s_{p g}$ in the gravity-based Eq. (6) leads us to the following estimating equation:

$\Delta \ln \operatorname{trade}_{p g}^{f}=\delta_{p}^{f}+\delta_{g}^{f}+\beta \cdot \underbrace{\Delta e r s_{p g} \cdot \ln \operatorname{dist}_{p g}}_{=\Delta R C_{p g}}+\epsilon_{p g}$,

where $\beta=\theta \tau$. Gateway- and province-flow fixed effects $\left(\delta_{p}^{f}, \delta_{g}^{f}\right)$ simply relabel [ $\Delta \ln \omega_{p}^{f}, \Delta \ln \omega_{g}^{f}$ ] in Eq. (6). For convenience, we denote the explanatory variable as the change in road capacity, $\Delta R C_{p g}=$
$\Delta e r s_{p g} \ln$ dist $_{p g}$. Since $\Delta e r s_{p g}>0$ for all $p g$ pairs, we expect $\beta$ to be positive: an increase in road capacity (and the corresponding decrease in transport costs) will increase trade.

While Eq. (7) identifies $\beta$, the underlying structural parameter of interest $\tau$ cannot be separately identified from the elasticity $\theta$ of trade flows to trade costs, as it is standard in the gravity literature (Anderson and van Wincoop, 2004). In what follows, we present $\beta$

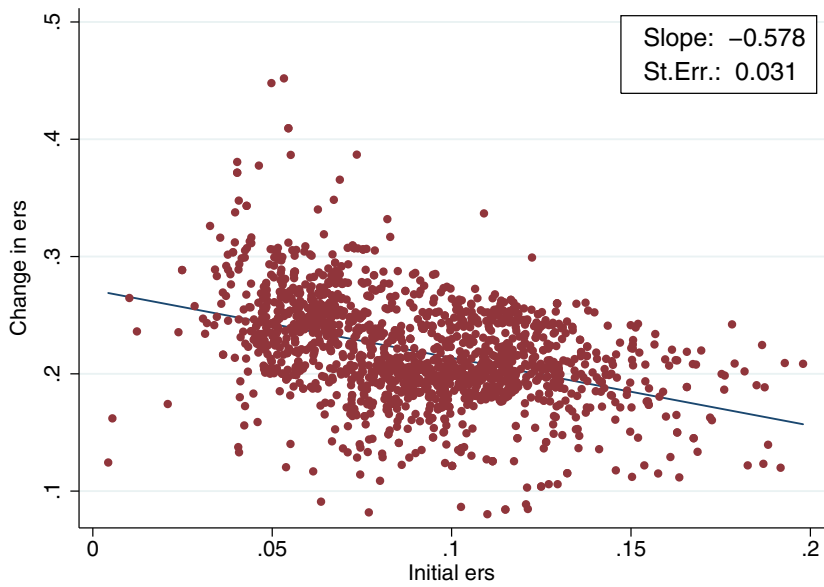

Fig. 5. Period change in the share of expressways and its initial value. Notes: The $x$-axis is the 2003 level of expressway share in roads connecting provinces and gateways ( ers $_{p g}^{2003}$ ). The $y$-axis is the period change in this variable $\left(\Delta e r s_{p g}\right)$.

Table 2

Gravity estimation.

\begin{tabular}{|c|c|c|c|c|}
\hline & (1) & (2) & (3) & (4) \\
\hline & \multicolumn{2}{|l|}{$\overline{\ln t r a d e_{p g}^{f}}$} & \multicolumn{2}{|l|}{$\overline{\text { trade }_{p g}^{f}}$} \\
\hline $\ln d_{i s t} t_{g}$ & $\begin{array}{l}-1.858^{* * *} \\
(0.084)\end{array}$ & $\begin{array}{l}-1.718^{* * *} \\
(0.072)\end{array}$ & $\begin{array}{l}-1.384^{\text {*** }} \\
(0.086)\end{array}$ & $\begin{array}{l}-1.222^{* * *} \\
(0.077)\end{array}$ \\
\hline Regression & OLS & OLS & PPML & PPML \\
\hline Observations & 1376 & 1859 & 2686 & 3180 \\
\hline$R^{2}$ & 0.638 & 0.657 & 0.981 & 0.972 \\
\hline Fixed effects & $p-f, g-f$ & $p-f, g-f$ & $p-f, g-f$ & $p-f, g-f$ \\
\hline Sample & 2003-04 & 2011-12 & 2003-04 & 2011-12 \\
\hline
\end{tabular}

Notes: All regressions are estimated with province-flow ( $\mathrm{p}-\mathrm{f}$ ) and gateway-flow ( $\mathrm{g}-\mathrm{f}$ ) fixed effects, where flows are exports or imports. Robust standard errors in parentheses. Significance: ${ }^{*} 10 \%$, ${ }^{* *} 5 \%$, ${ }^{* * *} 1 \%$. 


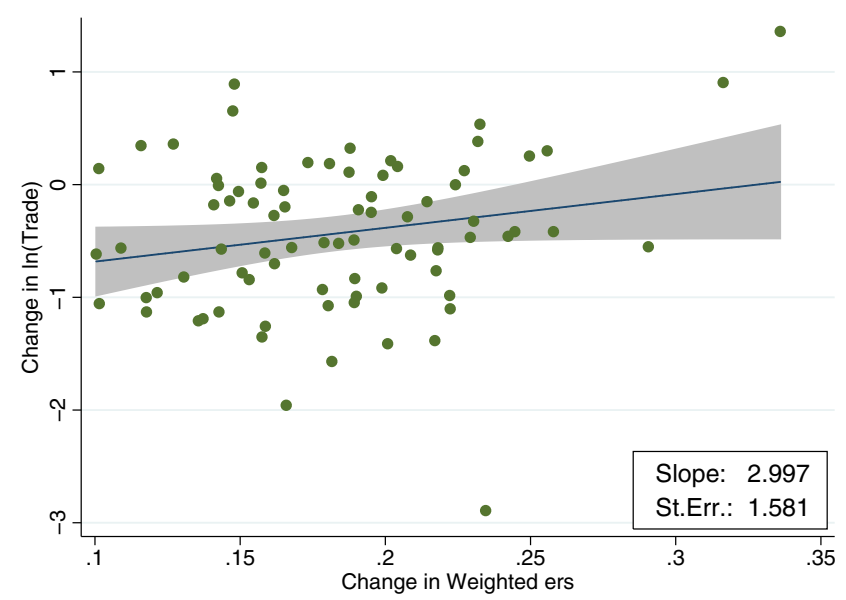

Fig. 6. Road capacity improvements and change in trade flows. Notes: The $x$-axis is the change in each province's connectivity to gateways over the 2003-2012 period defined as $\sum_{g} \pi_{p g} \cdot \Delta e r s_{p g}$, where $\pi_{p g}$ is the share of gateway $g$ in province $p$ 's total trade in 2003 and $\Delta e r s_{p g}$ is the change in the share of expressways in total road stock on the route between $p$ and $g$ between 2003 and 2012 - capturing the road quality improvement for a province in accessing foreign markets. The $y$-axis captures the period change in trade at the province-level. Please see text for details.

coefficients estimated from various specifications of Eq. (7) and use $\theta=$ 4 based on Simonovska and Waugh (2014) to calculate $\tau$ using the delta method. In various specifications below, we also control for the direct effect of $\Delta$ ers.

Table 3 presents the first set of results starting with OLS estimates. The individual effect of $\Delta$ ers in column 1 extends the analysis in Fig. 6 above and confirms its robustness in a finer level of aggregation. The OLS estimate of the coefficient on the variable of interest, $\Delta R C_{p g}$ in column 2 is significant at the $1 \%$ level. In column 3 , we add $\Delta e r s$ as an additional control. The estimate of $\beta$ retains its significance with a slight change in magnitude.

The specification presented in column 3 of Table 3 implies an estimate for $\tau$ that equals 0.186 with a standard error of $0.051 .{ }^{9}$ To give a sense of the transport cost reduction, take the PPML estimate from 2003-2004 (column 3 of Table 2 ) as $\tau_{s}=1.384$, as expressway road shares were very low at the beginning of our sample-i.e., while ers $>0$ for most of the routes in these initial years, we round it down to zero for the sake of this back-of-the-envelope calculation. This implies $\tau_{e}=\tau_{s}-0.186=1.198$. We use these elasticities in the transport cost function (3) to calculate the cost of shipping over the mean $p g$ distance of $820 \mathrm{~km}$ in our data when the road covering that distance is single carriageway versus expressway. We find that the cost of an averagedistance shipment drops by $70 \%$ if the complete route is upgraded from a single carriageway, i.e., from ers $=0$ to ers $=1$. This is a substantial drop in transport costs. ${ }^{10}$

To further quantify the effect, we calculate that each dollar spent on quality-improving investment in transport infrastructure generates a 10 -year discounted stream of trade flows between $\$ 0.7$ and $\$ 2$. The calculation is based on the specification presented in column 3 of Table 3 . We consider a hypothetical route with the mean distance $(820 \mathrm{~km})$ in the data. To reduce transport costs by $1 \%$ on this route, an additional $6.57 \mathrm{~km}$ of roads have to be transformed into divided roads. ${ }^{11}$ We

\footnotetext{
9 Since $\theta$ is an estimate itself, we calculate the expected value and the standard error of $\tau$ using the multivariate extension of the delta method. In particular, $E(\tau)=E(\beta / \theta) \approx \mu_{\beta} / \mu_{\theta}$ and $\operatorname{Var}(\tau) \approx\left(\mu_{\beta} / \mu_{\theta}\right)^{2}\left(\operatorname{Var}_{\beta} / \mu_{\beta}^{2}+\operatorname{Var}_{\theta} / \mu_{\theta}^{2}-2 \operatorname{Cov}(\beta, \theta) /\left(\mu_{\beta} \mu_{\theta}\right)\right)$. We take the mean and the variance of $\beta$ from 100 random samples of size 750. Using $\left(\mu_{\theta}=4.1, \operatorname{Var}_{\theta}=0.0081\right)$ from Table 5 of Simonovska and Waugh (2014), and assuming $\operatorname{Cov}(\beta, \theta)=0$, we impute $E(\tau)=0.186$ and $\operatorname{Var}(\tau)=0.051^{2}$.

${ }^{10}$ In the TC function, we set dist $=820$. Initially the share of expressways is zero, ers $=0$, and the corresponding value of $T C$ is dist $t_{s}^{\tau_{s}}=10,782$; and for ers $=1$, it is dist ${ }^{\tau_{e}}=3,095$.

${ }^{11}$ Given Eq. (3), the amount of road expansion (in $\mathrm{km}$ ) needed to decrease transport costs by $1 \%$ is given by: $\frac{0.01 * 820}{\tau \ln \frac{\ln }{\text { ist }_{p g}} \text {. }}$
}

calculate the average cost of building $6.57 \mathrm{~km}$ of a four-lane road over the 2003-2012 period. $^{12}$ Next, we use the estimated elasticity of $\tau$ based on the specification presented in column 3 of Table 3 to calculate the value of trade flows (at the mean) generated by a $1 \%$ decrease in transport costs. For discount factors between 0.15 and 0.05 , the present value of a 10-year stream of trade flows generated by a one-dollar investment in road infrastructure ranges between $\$ 0.7$ and $\$ 2 .{ }^{13}$

On overall, our results imply a sizeable effect of road capacity expansion on regional trade. There are several mechanisms through which the investment alleviated the negative impact of remoteness. Reduced congestion on main arteries implies a higher cruising speed for the vehicles on the road. Increased road capacity can also be associated with the observed fall in accidents: traffic-related fatalities per vehicle-km decreased by $40 \%$ from 2004 to 2011. A direct benefit of reduced accident rates is a possible reduction in freight insurance costs. Average cruising speed may also increase due to a lower probability of a road closure following an accident. All these benefits are likely to improve the timeliness and predictability of deliveries. Better road quality may also reduce transportation costs through reduced maintenance and depreciation costs in the logistics sector.

\subsubsection{Instrumental variable estimation}

We documented that the primary motivation behind the investment program was to relieve congestion and reduce the high rate of road accidents, which partly alleviates endogeneity concerns. Also, firstdifferencing implicitly controls for any time-invariant $p g$ level factors that might be correlated with the error term. Still, under a less likely scenario, policy-makers could favor some routes over others, for instance because there already existed strong exporters located in $p$ trying to reach a particular gateway $g$. To address such concerns, we estimate an instrumental variable model, using the initial share of expressways along $p g$ routes as an instrument. In doing so, we follow the literature estimating the impact of trade liberalization using as instrument initial tariff levels, (e.g. Amiti and Konings, 2007; Goldberg and Pavcnik, 2005; Topalova, 2010). The following facts suggest that initial expressway share (ers $\left.{ }_{p g, 2003}\right)$ is a valid and informative instrument for its change over the period under consideration. The public investment program aimed at "upgrading into expressways all the roads connecting the country to international markets and those connecting provincial centers." ${ }^{14}$ If fully achieved, upgrading all roads would bring all pairs into the same level, i.e., equal to one. While incomplete as of 2012, the investment program led to noticeable convergence in the share of expressways across $p g$ routes. This is confirmed by a substantial fall in its dispersion: the coefficient of variation fell from 0.34 in 2003 to 0.13 in 2012 (bottom panel of Table 1). For our purposes, the initial share of expressways becomes a good predictor of its change over this period. As illustrated in Fig. 5, there is a strong negative association between the initial share of expressways and its period change. A coefficient of -0.6 shows the degree of this catch-up.

We thus estimate Eq. (7) using a two-stage least squares model that instruments $\triangle R C_{p g}$ in the following first stage:

$$
\Delta R C_{p g}=\gamma_{p}+\gamma_{g}+\alpha_{1}\left(\operatorname{ers}_{p g, 2003}-1\right) \ln \operatorname{dist}_{p g}+\alpha_{2} \ln d i s t_{p g}+\eta_{p g}
$$

\footnotetext{
12 The average cost of building a $1 \mathrm{~km}$ of a four-lane road is $\$ 1.1$ million over this period (Directorate of Strategy Development of the Ministry of Finance, 2011, "POLITIKA ANALizi: ULAŞTIRMA SEKTÖRÜ BÖLÜNMÜŞ YOL ÇALIŞMASI).” The report is available from the authors upon request.

${ }^{13}$ Note that this calculation does not reflect the rate of return to investment since it does not take into account within-country trade. Doing so, Allen and Arkolakis (2014) estimate a rate of return for the US Interstate Highway System around $100 \%$.

${ }^{14}$ See the bottom bullet point in page 55 of the policy document "TÜRKIYE ULAȘIM VE İLETIŞIM STRATEJISİ-HEDEF 2023" published by the Ministry of Transport, Maritime and Communications of the Republic of Turkey, available at http://www.izmiriplanliyorum. org/static/upload/file/turkiye_2023_ulasim_ve_iletisim_stratejisi.pdf.
} 
Table 3

Baseline results.

\begin{tabular}{|c|c|c|c|c|c|c|c|}
\hline & (1) & (2) & (3) & (4) & (5) & (6) & (7) \\
\hline & $\Delta \ln$ trade $_{p g}^{f}$ & $\Delta \ln$ trade $_{p g}^{f}$ & $\Delta \ln$ trade $_{p g}^{f}$ & $\Delta \ln$ trade $_{p g}^{f}$ & $\Delta R C_{p g}$ & $\Delta \ln$ trade $_{p g}^{f}$ & $\Delta \ln$ trade $_{p g}^{f}$ \\
\hline$\Delta e r s_{p g}$ & $\begin{array}{l}5.812^{* *} \\
(2.751)\end{array}$ & & $\begin{array}{l}0.610 \\
(4.098)\end{array}$ & $\begin{array}{l}21.06^{* *} \\
(9.370)\end{array}$ & & & $\begin{array}{l}0.859 \\
(7.207)\end{array}$ \\
\hline$\Delta R C_{p g}$ & & $\begin{array}{l}0.875^{* * * *} \\
(0.322)\end{array}$ & $\begin{array}{l}0.822^{*} \\
(0.480)\end{array}$ & & & $\begin{array}{l}0.966^{* *} \\
(0.378)\end{array}$ & $\begin{array}{l}0.858^{*} \\
(0.469)\end{array}$ \\
\hline$\left(e r s_{p g}^{2003}-1\right) \times \ln \operatorname{dist}_{p g}$ & & & & & $\begin{array}{l}-0.279^{* * *} \\
(0.0456)\end{array}$ & & \\
\hline $\ln$ dist $_{p g}$ & & & & & $\begin{array}{l}-0.0179 \\
(0.0416)\end{array}$ & & \\
\hline Regression & OLS & OLS & OLS & IV & OLS & IV & IV \\
\hline Observations & 1015 & 1015 & 1015 & 1015 & 1015 & 1015 & 1015 \\
\hline$R^{2}$ & 0.338 & 0.340 & 0.340 & 0.313 & 0.818 & 0.340 & 0.340 \\
\hline Fixed effects & $p-f, g-f$ & $p-f, g-f$ & $p-f, g-f$ & $p-f, g-f$ & $p-f, g-f$ & $p-f, g-f$ & $p-f, g-f$ \\
\hline AR test stat. & & & & 4.315 & & 4.044 & 2.695 \\
\hline KP test stat. & & & & 55.92 & & 548.9 & 40.59 \\
\hline DWH test stat. & & & & 2.795 & & 0.113 & 0.129 \\
\hline
\end{tabular}

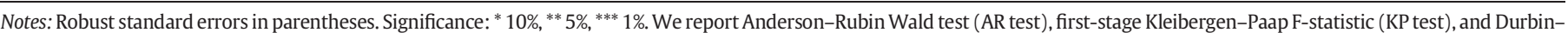
Wu-Hausman F-statistic (DWH test).

First-stage results are presented in column 5 of Table 3 . Since the instrument is the initial level of log transport costs, the term ln dist $t_{p g}$ does not drop out in the first stage. ${ }^{15}$ The value of the Kleibergen-Paap Fstatistic is high, suggesting that our IV estimates are not likely to suffer from bias due to weak instruments. Columns 6 and 7 present the estimation results from the second-stage. The estimated coefficients on $\Delta R C_{p g}$ are still significant at the $5 \%$ and $10 \%$ levels. ${ }^{16}$ While the IV estimates in columns (6)-(7) are slightly larger than the OLS estimates in columns (2)-(3), Durbin-Wu-Hausman test suggests that the OLS estimate is consistent at any conventional significance level.

Finally, to strengthen our argument about the validity of the instrument, we test the robustness of our results to deviations from the assumption of perfect exogeneity. To do so, we follow the method proposed by Conley et al. (2012) and convincingly applied by Nunn and Wantchekon (2011). The test relaxes the assumption of perfect exogeneity and assumes a flexible second-stage regression that also includes the instrument as a regressor. If the coefficient on the instrument in the second-stage regression is known, one can obtain consistent estimates of the effect of $\Delta R C_{p g}$ on the dependent variable. To implement this method in our setting, we need a consistent estimate of the direct effect of the initial level of transport costs along a pg route on the change in bilateral trade flows. For the estimation of this direct effect, we exploit the fact that only a tiny share of roads was converted into expressways in the first year of the investment period. ${ }^{17}$ Given that $\Delta R C_{p g}$ is close to zero between 2003-2004, we can estimate the following equation for 2003-2004:

$\Delta \operatorname{trade}_{p g}^{f}=\delta_{p}^{f}+\delta_{g}^{f}+\alpha\left(\operatorname{ers}_{p g, 2003}-1\right) \ln \left(\operatorname{dist}_{p g}\right)+\epsilon_{p g}^{f}$.

The coefficient on $\left(e r s_{p g, 2003}-1\right) \ln \left(\right.$ dist $\left._{p g}\right)$ is estimated to be positive (0.07) but insignificant. If we assume that $\alpha$ varies on the interval $[0,0.07]$, there is $90 \%$ probability that our coefficient of interest $\beta$ would vary between $[0.34,1.86]$. Indeed, any positive value of $\alpha$

\footnotetext{
15 More precisely, we are essentially instrumenting $\Delta\left[\tau\left(1-e r s_{p g}\right) \ln\right.$ dist $_{p g}+\tau_{e} \ln$ dist $\left._{p g}\right]$, the change in (log) transport costs, with its 2003 level. The instrumented variable $\Delta R C_{p g}=\Delta e r s_{p g}$ ln dist $_{p g}$ in the estimating Eq. (7) simply follows from cancelling the time-invariant term $\tau_{e} \ln$ dist $_{p g}$ by differencing, reversing the sign by $\Delta\left(1-e r s_{p g}\right)=-\Delta e r s_{p g}$ and absorbing $\tau$ in $\beta=\theta \tau$.

${ }^{16}$ A similar back-of-the-envelope calculation using the estimate of $\tau$ from column $6 \mathrm{im}$ plies that transforming all single carriage roads into expressways reduces the cost of shipping over the mean $p g$ distance in our data by $75 \%$.

17 In particular, the 99th percentile of the change in the share of expressways between 2003-2004 (0.06) is almost half of the first percentile of its cumulative change over the entire period $(0.11)$. We still restrict the sample to $p g$ pairs with an annual increase below 0.02 , which corresponds to the 10th percentile of the distribution of $\Delta e r s_{p g}^{03-04}$
}

would imply a positive estimate for $\beta$, with estimates increasing in the value of $\alpha$. This exercise shows that our earlier findings are robust to relaxing the assumption of strict instrument exogeneity.

\subsubsection{Additional controls and alternative specifications}

Table 4 checks the robustness of results to the inclusion of relevant controls. Column 1 directly includes the initial level of ers and its interaction with log distance as independent variables instead of using them as instruments. In column 2, we add distance as an additional control to

Table 4

Additional controls.

\begin{tabular}{|c|c|c|c|c|c|}
\hline & (1) & (2) & (3) & (4) & (5) \\
\hline & $\begin{array}{l}\Delta \ln \\
\text { trade }_{p g}^{f}\end{array}$ & $\begin{array}{l}\Delta \ln \\
\text { trade }_{p g}^{f}\end{array}$ & $\begin{array}{l}\Delta \ln \\
\text { trade }_{p g}^{f}\end{array}$ & $\begin{array}{l}\Delta \ln \\
\text { trade }_{p g}^{f}\end{array}$ & $\begin{array}{l}\Delta \ln \\
\text { trade }_{p g}^{f}\end{array}$ \\
\hline$\Delta R C_{p g}$ & $\begin{array}{l}1.975^{*} \\
(1.184)\end{array}$ & $\begin{array}{l}1.297^{* *} \\
(0.620)\end{array}$ & $\begin{array}{l}1.250^{* *} \\
(0.620)\end{array}$ & $\begin{array}{l}1.391^{* *} \\
(0.627)\end{array}$ & $\begin{array}{l}2.180^{* * * *} \\
(0.699)\end{array}$ \\
\hline$\Delta e r s_{p g}$ & $\begin{array}{c}-6.388 \\
(6.854)\end{array}$ & $\begin{array}{l}-2.380 \\
(7.262)\end{array}$ & $\begin{array}{l}-3.874 \\
(7.531)\end{array}$ & $\begin{array}{l}-3.793 \\
(7.355)\end{array}$ & $\begin{array}{l}-3.620 \\
(7.345)\end{array}$ \\
\hline $\operatorname{ers}_{p g}^{2003} \times \ln$ dist $_{p g}$ & $\begin{array}{l}-2.418 \\
(2.302)\end{array}$ & & & & \\
\hline$e r s_{p g}^{2003}$ & $\begin{array}{l}8.087 \\
(14.54)\end{array}$ & & & & \\
\hline$I\left\{\right.$ dist $_{p g}>$ median $\}$ & & $\begin{array}{l}-0.182 \\
(0.201)\end{array}$ & $\begin{array}{l}-0.185 \\
(0.201)\end{array}$ & $\begin{array}{l}-0.158 \\
(0.203)\end{array}$ & $\begin{array}{c}-0.268 \\
(0.206)\end{array}$ \\
\hline$\Delta \ln P G D P_{p g}^{04-11}$ & & & $\begin{array}{l}1.725 \\
(1.943)\end{array}$ & $\begin{array}{l}1.160 \\
(1.990)\end{array}$ & $\begin{array}{l}0.771 \\
(1.997)\end{array}$ \\
\hline$\Delta \ln \operatorname{trade}_{p g}^{96-01}$ & & & & $\begin{array}{l}1.291 \\
(1.496)\end{array}$ & $\begin{array}{l}1.528 \\
(1.498)\end{array}$ \\
\hline$\Delta \ln \operatorname{trade}_{p g}^{96-01} \times \ln$ dist $_{p g}$ & & & & $\begin{array}{l}-0.257 \\
(0.248)\end{array}$ & $\begin{array}{c}-0.298 \\
(0.248)\end{array}$ \\
\hline$\left(M A_{p} \times S A_{g}\right)$ & & & & & $\begin{array}{l}4.699 * * \\
(1.955)\end{array}$ \\
\hline$\left(M A_{p} \times S A_{g}\right) \times \ln d i s t_{p g}$ & & & & & $\begin{array}{l}-0.794^{* *} \\
(0.327)\end{array}$ \\
\hline Regression & OLS & IV & IV & IV & IV \\
\hline Observations & 1015 & 1015 & 1015 & 1015 & 1015 \\
\hline$R^{2}$ & 0.343 & 0.341 & 0.341 & 0.343 & 0.346 \\
\hline Fixed effects & $p-f, g-f$ & $p-f, g-f$ & $p-f, g-f$ & $p-f, g-f$ & $p-f, g-f$ \\
\hline AR test stat. & & 2.599 & 2.328 & 1.935 & 3.096 \\
\hline KP test stat. & & 38.59 & 32.05 & 33.64 & \\
\hline DWH test stat. & & 0.211 & 0.358 & 0.224 & 0.411 \\
\hline
\end{tabular}

Notes: $M A_{p}, S A_{g}$ are market and supply access of provinces and gateways, respectively. They are estimated fixed effects from the gravity estimation in Table 2 . I\{dist ${ }_{p g}>$ median $\}$ is a dummy variable that takes on the value one if dist $t_{p g}$ is above its median value in the data, and zero otherwise. $\triangle \ln P G D P$ is per capita GDP change in the $p g$ route, available between 2004-2011 only. $\Delta \ln$ trade $_{p g}^{96-01}$ is the total trade change in the $p g$ route between 1996-2001. Robust standard errors in parentheses. Significance: ${ }^{*} 10 \%,{ }^{* *} 5 \%$, ${ }^{* * *} 1 \%$. We report Anderson-Rubin Wald test (AR test), first-stage Kleibergen-Paap F-statistic (KP test), and Durbin-Wu-Hausman F-statistic (DWH test). 
the baseline specification to check whether flows at longer distances (above median) have different trends than those at shorter distances (below median). The coefficient on above-median distance dummy is estimated to be insignificant while our coefficient of interest retains its significance. Columns 3 controls for the period change in per capita income in each pg route. ${ }^{18}$ The next column adds the change in total trade flows over the 1996-2001 period in each $p g$ route and its interaction with distance. Controlling for trade change prior to the investment period addresses the concern that some routes may have been selected for their past trade performance or the routes receiving above average investment may have been on a spurious upward trend. Column 5 adds as controls the fixed effects estimated from the baseline gravity specification (2) in Table 2 and their interaction with log distance to proxy for market and supplier access as in Redding and Venables (2004). While there is some variation in point estimates, the qualitative results largely survive these checks.

We also subject the analysis to alternative specifications and report the IV results in Table 5 . In column 1, we exclude origin and destination provinces from the construction of expressway road shares and define the "between" measure as $\Delta e r s_{p g}^{b w}=\frac{\sum_{j \in J_{p g} \& j \neq\{p, g\}} \Delta_{j \in J_{p g} \& j \neq\{p, g\}} \text { roadstock }_{j, 2003}}{\sum_{j}}$. The result shows that the explanatory power comes from in-between provinces alone.

In columns 2 and 3, we replace the trade cost function (3) with alternative specifications. We first let

$T C_{p g t}=\exp \left(\tau_{e} \cdot\left[\right.\right.$ ers $\left.\left._{p g t} d i s t_{p g}\right]+\tau_{s} \cdot\left[\left(1-e r s_{p g t}\right) d i s t_{p g}\right]\right)$.

Making the appropriate substitutions, taking natural logarithms and long-differences yields a semi-elasticity specification where the independent variable is $\Delta e r s_{p g} \times$ dist $_{p g}$. While the coefficient in column 2 is no longer comparable to the baseline, the estimate is of the right sign and significant at the $5 \%$ level.

We then let trade costs be a function of travel times: $T C_{p g t}=$ $\exp \left(\gamma \cdot\right.$ time $\left._{p g t}\right)$. Given $\left(v_{s}, v_{e}\right)$, the velocity of trucks on single carriageways and expressways, travel time between $p$ and $g$ is

time $_{p g}=\frac{e r s_{p g} \operatorname{dist}_{p g}}{v_{e}}+\frac{\left(1-e r s_{p g}\right) \text { dist }_{p g}}{v_{s}}$.

Repeating the algebra, we get

$\Delta \ln T C_{p g}=\gamma \Delta \operatorname{time}_{p g}=\gamma\left[\Delta \operatorname{ers} p g \cdot \operatorname{dist}_{p g}\left(\frac{1}{v_{e}}-\frac{1}{v_{s}}\right)\right]$.

Substituting this into Eq. (6) allows us to identify $\theta \gamma$ from time variation in ers. Thus, the gains from the road investment in this case directly accrue from reduced travel times on expressways. ${ }^{19}$ The estimate in the third column of Table 5, instrumenting $\Delta \ln T C_{p g}$ with time $e_{p g}^{2003}$, implies $\gamma=0.522$ and a reduction of travel costs around $27 \%$ on an average stretch of $820 \mathrm{~km}$ upon upgrading.

We documented the establishment of new trade links between $p g$ pairs over time in Table 1 . To incorporate this extensive margin improvement into our analysis, we define the dependent variable as $2 \cdot\left(\right.$ trade $\left._{p g, 2012}^{f}-\operatorname{trade}_{p g, 2003}^{f}\right) /\left(\operatorname{trade}_{p g, 2012}^{f}+\operatorname{trade}_{p g, 2003}^{f}\right)$ and report the IV estimate in the 4 th column of Table 5 . Ranging between -2 and 2 , this measure incorporates all $p g$ pairs that have a trade relationship in 2003 or 2012. As a result, the sample size increases from 1015 observations to 1687 . The estimate has the expected sign and is significant at the $1 \%$ level.

\footnotetext{
18 Province-level income data have not been published in Turkey since 2002. The only available data start from 2004 and are at the NUTS2 level.

${ }^{19}$ We use the official speed limits for expressways and single carriageways in Turkey ( $v_{e}=85 \mathrm{~km} / \mathrm{h}$ and $v_{s}=80 \mathrm{~km} / \mathrm{h}$, obtained from the following website on September 2015: http://www.kgm.gov.tr/Sayfalar/KGM/SiteTr/Trafik/HizSinirlari.aspx).
}

Table 5

Alternative specifications

\begin{tabular}{|c|c|c|c|c|}
\hline & (1) & (2) & (3) & (4) \\
\hline & $\Delta \ln$ trade $_{p g}^{f}$ & $\Delta \ln$ trade $_{p g}^{f}$ & $\Delta \ln$ trade $_{p g}^{f}$ & 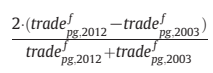 \\
\hline$\Delta R C_{p g}^{b w}$ & $\begin{array}{l}0.911^{*} \\
(0.466)\end{array}$ & & & \\
\hline$\Delta e r s_{p g}^{b w}$ & $\begin{array}{l}-4.337 \\
(2.772)\end{array}$ & & & \\
\hline$\Delta e r s_{p g} \times$ dist $_{p g}$ & & $\begin{array}{l}0.207^{* *} \\
(0.0902)\end{array}$ & & \\
\hline$\Delta e r s_{p g}$ & & $\begin{array}{l}5.290 \\
(5.561)\end{array}$ & $\begin{array}{l}21.95^{* *} \\
(9.290)\end{array}$ & $\begin{array}{l}-9.008^{* * * *} \\
(2.427)\end{array}$ \\
\hline$\Delta$ time $_{p g}$ & & & $\begin{array}{l}-2.086^{*} \\
(1.260)\end{array}$ & \\
\hline$\Delta R C_{p g}$ & & & & $\begin{array}{l}0.867^{* * *} \\
(0.154)\end{array}$ \\
\hline Regression & IV & IV & IV & IV \\
\hline Observations & 1015 & 1015 & 1015 & 1687 \\
\hline$R^{2}$ & 0.338 & 0.342 & 0.311 & 0.259 \\
\hline Fixed Effects & p-f,g-f & p-f,g-f & $p-f, g-f$ & p-f,g-f \\
\hline AR test stat. & 1.757 & 3.303 & 4.911 & 10.82 \\
\hline KP test stat. & 37.56 & 53.84 & 29.91 & 53.28 \\
\hline DWH test stat. & 1.869 & 0.0481 & 1.606 & 2.771 \\
\hline
\end{tabular}

Notes: Distance units in column 2 is in $100 \mathrm{~km}$. Robust standard errors in parentheses. Significance: ${ }^{*} 10 \%, * * 5 \%, * * 1 \%$. We report Anderson-Rubin Wald test (AR test), first-stage Kleibergen-Paap F-statistic (KP test).

In order to investigate further whether the baseline estimates are subject to selection bias arising from the fact that they are based on a sample of $p g$ pairs that have always traded with each other over the 2003-2012 period, we follow the approach suggested by Mulligan and Rubinstein (2008) and report the results in Table 6. We first estimate the probability of observing positive trade for a pg pair in both 2003 and 2012, and obtain predicted selection probabilities. We then estimate Eq. (7), also controlling for $\Delta e r s_{p g}$, on subsamples determined by the predicted selection probabilities, i.e. subsamples of $p g$ pairs with

Table 6

Controlling for selection.

\begin{tabular}{|c|c|c|c|c|c|c|}
\hline & (1) & (2) & (3) & (4) & (5) & (6) \\
\hline & Select & $\begin{array}{l}\Delta \ln \\
\text { trade }_{p g}^{f}\end{array}$ & $\begin{array}{l}\Delta \ln \\
\text { trade }_{p g}^{f}\end{array}$ & $\begin{array}{l}\Delta \ln \\
\text { trade }_{p g}^{f}\end{array}$ & $\begin{array}{l}\Delta \ln \\
\text { trade }_{p g}^{f}\end{array}$ & $\begin{array}{l}\Delta \ln \\
\text { trade }_{p g}^{f}\end{array}$ \\
\hline $\begin{array}{l}\left(\operatorname{ers}_{p g}^{2003}-1\right) \times \ln \\
\quad \operatorname{dist}_{p g} \\
\text { ln dist } \\
\text { dig }\end{array}$ & $\begin{array}{l}-0.468 \\
(5.167) \\
-1.370 \\
(4.704)\end{array}$ & & & & & \\
\hline In trade $f_{p g, 2003}^{f}$ & $\begin{array}{l}0.151^{* * * *} \\
(0.0359)\end{array}$ & & & & & \\
\hline$e r s_{p g}^{2003}$ & $\begin{array}{l}2.357 \\
(33.99)\end{array}$ & & & & & \\
\hline$\Delta R C_{p g}$ & & $\begin{array}{l}0.858^{*} \\
(0.469)\end{array}$ & $\begin{array}{l}0.980^{* *} \\
(0.470)\end{array}$ & $\begin{array}{l}0.988^{* *} \\
(0.458)\end{array}$ & $\begin{array}{l}0.769 \\
(0.474)\end{array}$ & $\begin{array}{l}1.045^{* *} \\
(0.483)\end{array}$ \\
\hline$\Delta e r s_{p g}$ & & $\begin{array}{l}0.859 \\
(7.207)\end{array}$ & $\begin{array}{l}-1.606 \\
(7.300)\end{array}$ & $\begin{array}{c}-1.489 \\
(7.044)\end{array}$ & $\begin{array}{c}-1.979 \\
(6.982)\end{array}$ & $\begin{array}{c}-3.361 \\
(6.508)\end{array}$ \\
\hline Regression & Probit & IV & IV & IV & IV & IV \\
\hline Sample & & All & $\begin{array}{l}>10 \text { th } \\
\text { pctl }\end{array}$ & $\begin{array}{l}>25 t h \\
\text { pctl }\end{array}$ & $\begin{array}{l}>50 t h \\
\text { pctl }\end{array}$ & $\begin{array}{l}>60 \text { th } \\
\text { pctl }\end{array}$ \\
\hline Observations & 765 & 1015 & 996 & 921 & 748 & 672 \\
\hline$R^{2}$ & & 0.340 & 0.349 & 0.343 & 0.455 & 0.477 \\
\hline Fixed Effects & $\mathrm{p}, \mathrm{g}$ & $p-f, g-f$ & $p-f, g-f$ & $p-f, g-f$ & $p-f, g-f$ & $p-f, g-f$ \\
\hline AR test stat. & & 2.695 & 3.048 & 2.349 & 1.134 & 1.911 \\
\hline KP test stat. & & 40.59 & 39.51 & 42.08 & 41.29 & 39.31 \\
\hline DWH test stat. & & 0.129 & 0.217 & 0.0758 & 0.151 & 0.288 \\
\hline
\end{tabular}

Notes: Select $p_{p g}$ is an indicator variable that is equal to one if 2003 and 2012 trade flows are both positive, and zero otherwise. Sample in columns 3-5 are constructed based on the predicted probabilities from column (1). Robust standard errors in parentheses. We report Anderson-Rubin Wald test (AR test), first-stage Kleibergen-Paap F-statistic (KP test), and Durbin-Wu-Hausman F-statistic (DWH test). Hausman test stat. in the last column refers to the test statistic of a generalized Hausman test of the hypothesis that difference in coefficients between columns 3-6 is zero. Significance: ${ }^{*} 10 \%,{ }^{*} 5 \%$, ${ }^{* * *} 1 \%$. 
the predicted probabilities above certain percentiles of the selection probability distribution. If our intensive margin estimates are not subject to serious selection bias, then estimates obtained from different subsamples should be close to the one obtained from the whole sample. First column of Table 6 shows that, after controlling for province and gateway fixed effects, the initial volume of bilateral trade flows is the only statistically significant determinant of the probability of observing positive trade for a $p g$ pair in both years. ${ }^{20}$ Column 2 replicates the baseline IV estimation presented in column 7 of Table 3. Columns 3 to 6 show the results obtained from the estimation of Eq. (7) on subsamples of $p g$ pairs with the predicted probabilities above the 10th, 25th, 50th and 60th percentiles of the selection distribution. The coefficient estimates are not statistically different from the one presented in column 2. A generalized Hausman test of the hypothesis that difference in coefficients between columns 3-6 is zero gives a value of 2.340, with an associated p-value of 0.505 . We thus conclude that our estimate of the intensive margin elasticity of trade flows with respect to road capacity is not subject to serious selection bias. ${ }^{21}$

\subsubsection{Extensive margin}

To further investigate the effect of road capacity improvements in the initiation of new trade flows through gateways, we estimate a linear probability model in which we replace the dependent variable in Eq. (7) with a binary variable $\mathrm{New}_{p g}^{f}$ that takes the value one if a new provincegateway trade link has started, i.e., trade $e_{p g}^{f}$ turns from zero in 2003 to positive in 2012, and zero otherwise. Table 7 presents the results. ${ }^{22}$ According to our IV estimate (column 1), a one percent increase in road capacity increases the probability of a new trade link by 0.088 . The estimated value of the coefficient increases slightly when the period change in the share of expressways is controlled for (column 2). The result is robust to using the between-provinces measure in column 3 and adding additional controls in columns 4-6.

Given the specialization of ports in industries and in partner countries, a new pg link implies that province $p$ trades with new partners in new industries. We now look into these margins of the observed trade expansion at the pg-level, namely the country (trade partner) and industry dimensions of our data. We decompose pg-level trade into the number of countries or industries traded, and the average volume of trade per pgc or pgi. We estimate Eq. (7) for both margins and present the results in Table 8. Columns 1 and 4 replicate the baseline IV results in column 7 of Table 3, while columns 2-3 and 5-6 feature the intensive-extensive margin decompositions. For both dimensions, the intensive margin is insignificant despite having the right sign. In the extensive margin, $p g c$-level effects are significant (column 3 ) at the $10 \%$ level. Around one-third of the overall trade increase is due to the extensive margin $(0.286 / 0.858)$, i.e., establishment of links with new trade partners. The extensive margin is also significant at the industry dimension, and it accounts for about $87 \%$ of the trade increase $(0.757 / 0.858)$. By identifying the channels in terms of industries and destination/source countries, these results complement the finding

\footnotetext{
${ }^{20}$ Number of observations drops in the first column of Table 6 because some fixed effects predict failure or success perfectly.

21 As an additional robustness check, we use the generalized propensity score (GPS) method developed by Hirano and Imbens (2004), which is an extension of the standard PS approach to cases with continuous treatment. Results show that the level of treatment $\left(\Delta R C_{p g}\right)$ is significantly associated with only the initial share of expressways along the route, $e r s_{p g}^{2003}$. The fact that other pre-treatment variables do not significantly explain $\Delta R C_{p g}$ supports the hypothesis that our instrument is valid. The estimated dose-response function and the corresponding 95\% confidence bands show that the marginal effect of $\Delta R C_{p g}$ on $p g$-level trade is highly significant and varies around one-which is consistent with the estimate of $\beta$ we obtain from the baseline OLS/IV regressions in Table 3. This exercise provides an external validity check of the OLS/IV analysis. GPS results are available from the authors on request.

22 Probit and IVProbit estimates are qualitatively and quantitatively similar to LPM and IVLPM estimates. The reason we report the latter is that linear models provide a more flexible approach in the presence of many fixed effects. Probit and IVProbit results are available from the authors.
}

Table 7

New Province-Gateway Trade Links.

\begin{tabular}{|c|c|c|c|c|c|c|}
\hline & (1) & (2) & (3) & (4) & (5) & (6) \\
\hline & $N e w_{p g}^{f}$ & $\mathrm{New}_{p g}^{f}$ & $N e w_{p g}^{f}$ & $\mathrm{New}_{p g}^{f}$ & $N e w_{p g}^{f}$ & $\mathrm{New}_{p g}^{f}$ \\
\hline$\Delta R C_{p g}$ & $\begin{array}{l}0.0881^{*} \\
(0.0507)\end{array}$ & $\begin{array}{l}0.107^{* *} \\
(0.0498)\end{array}$ & & $\begin{array}{l}0.187^{* *} \\
(0.0772)\end{array}$ & $\begin{array}{l}0.186^{* *} \\
(0.0786)\end{array}$ & $\begin{array}{l}0.364^{* * *} \\
(0.0919)\end{array}$ \\
\hline$\Delta e r s_{p g}$ & & $\begin{array}{l}2.833^{* * * *} \\
(0.889)\end{array}$ & & $\begin{array}{l}2.261^{* *} \\
(0.973)\end{array}$ & $\begin{array}{l}2.293^{* *} \\
(0.963)\end{array}$ & $\begin{array}{l}-1.304 \\
(1.005)\end{array}$ \\
\hline$\Delta R C_{p g}^{b w}$ & & & $\begin{array}{l}0.103^{* *} \\
(0.0522)\end{array}$ & & & \\
\hline$\Delta e r s_{p g}^{b w}$ & & & $\begin{array}{l}-0.868^{* * *} \\
(0.322)\end{array}$ & & & \\
\hline $\begin{array}{l}I\left\{\text { dist }_{p g}>\right. \\
\quad \text { median }\}\end{array}$ & & & & $\begin{array}{l}-0.0290 \\
(0.0221)\end{array}$ & $\begin{array}{l}-0.0290 \\
(0.0221)\end{array}$ & $\begin{array}{l}-0.0452^{*} \\
(0.0240)\end{array}$ \\
\hline $\begin{array}{l}\Delta \ln \\
\quad P G D P_{p g}^{04-11}\end{array}$ & & & & & $\begin{array}{l}0.0118 \\
(0.230)\end{array}$ & $\begin{array}{l}-0.180 \\
(0.246)\end{array}$ \\
\hline $\begin{array}{l}\Delta \ln \\
\quad \operatorname{trade}_{p g}^{96-01}\end{array}$ & & & & & & $\begin{array}{l}-0.0905 \\
(0.197)\end{array}$ \\
\hline $\begin{array}{l}\Delta \ln \\
\quad \text { trade }_{p g}^{96-01} \\
\quad \times \ln \text { dist }_{p g}\end{array}$ & & & & & & $\begin{array}{l}0.0124 \\
(0.0314)\end{array}$ \\
\hline$M A_{p} \times S A_{g}$ & & & & & & $\begin{array}{l}-0.250 \\
(0.220)\end{array}$ \\
\hline $\begin{array}{l}\left(M A_{p} * S A_{g}\right) \times \\
\ln \text { dist }_{p g}\end{array}$ & & & & & & $\begin{array}{l}0.0233 \\
(0.0385)\end{array}$ \\
\hline Regression & IV & IV & IV & IV & IV & IV \\
\hline Observations & 3200 & 3200 & 3200 & 3200 & 3200 & 2669 \\
\hline$R^{2}$ & 0.152 & 0.115 & 0.149 & 0.117 & 0.117 & 0.133 \\
\hline Fixed Effects & p-f,g-f & $p-f, g-f$ & $p-f, g-f$ & $p-f, g-f$ & $p-f, g-f$ & $p-f, g-f$ \\
\hline AR test stat. & 1.401 & 12.23 & 2.526 & 13.47 & 13.79 & 7.330 \\
\hline KP test stat. & 755.5 & 66.68 & 54.27 & 65.42 & 66.90 & 67.65 \\
\hline DWH test & 0.233 & 8.621 & 3.429 & 8.980 & 2.579 & 2.579 \\
\hline
\end{tabular}

stat.

Notes: $N e w_{p g}$ is equal to $\operatorname{Pr}\left(\right.$ trade $_{p g}^{f, P o s t}>0 \&$ trade $\left._{p g}^{f, P r e}=0\right)$. Robust standard errors in parentheses. For variable descriptions, see the notes to Table 4 . Significance: ${ }^{*} 10 \%,{ }^{*}{ }^{*} 5 \%$, ${ }^{* * *} 1 \%$. We report Anderson-Rubin Wald test (AR test), first-stage Kleibergen-Paap F-statistic (KP test), and Durbin-Wu-Hausman F-statistic (DWH test).

that improvements in road capacity were associated with increased trade within $p g$ pairs.

We finish this subsection by asking whether intensive and extensive margin results differ when estimated for imports and exports separately, rather than using the pooled sample as we did so far. ${ }^{23}$ Table 9 shows that for imports, it is the intensive margin that matters while for exports, the extensive margin of reaching new ports is the key driver.

\subsection{Road capacity and transportation intensive industries}

Having documented the trade-enhancing effect of expressway construction, we now explore a potential channel through which this increase may have materialized. One would expect that the more transportation-intensive an industry is, the greater the impact of improved road capacity on its trade would be. This may be due to two industry characteristics: sensitivity to the length and precision of delivery times, and the heaviness of it inputs or outputs.

For some agricultural goods, time-sensitivity may arise simply due to perishability. The literature recognizes other causes as well: for intermediate goods that are part of international supply chains, timeliness and predictability of delivery times are crucial. Industries with volatile demand for customized products display high demand for fast and frequent shipments of small volumes (Evans and Harrigan, 2005). Timein-transit also constitutes a direct inventory-holding cost itself. Using data on US imports disaggregated by mode of transportation, Hummels and Schaur (2013) exploit the variation in the premium paid for air shipping and in time lags for ocean transit to identify the

\footnotetext{
${ }^{23}$ To be able to make comparisons across flows, we restrict the sample to pg pairs for which we observe both trade flows in the data.
} 
Table 8

Trade partner and industry margins of trade.

\begin{tabular}{|c|c|c|c|c|c|c|}
\hline & (1) & (2) & (3) & (4) & (5) & (6) \\
\hline & \multicolumn{3}{|l|}{ Countries } & \multicolumn{3}{|l|}{ Industries } \\
\hline & $\Delta \ln$ trade $_{p g}^{f}$ & $\Delta \ln \left(\operatorname{trade}_{p g}^{f} / N_{p g}^{f}\right)$ & $\Delta \ln N_{p g}^{f}$ & $\Delta \ln \operatorname{trade}_{p g}^{f}$ & $\Delta \ln \left(\operatorname{trade}_{p g}^{f} / N_{p g}^{f}\right)$ & $\Delta \ln N_{p g}^{f}$ \\
\hline$\Delta R C_{p g}$ & $\begin{array}{l}0.858^{*} \\
(0.469)\end{array}$ & $\begin{array}{l}0.572 \\
(0.411)\end{array}$ & $\begin{array}{l}0.286^{*} \\
(0.167)\end{array}$ & $\begin{array}{l}0.858^{*} \\
(0.469)\end{array}$ & $\begin{array}{l}0.108 \\
(0.418)\end{array}$ & $\begin{array}{l}0.750^{* * * *} \\
(0.153)\end{array}$ \\
\hline$\Delta e r s_{p g}$ & $\begin{array}{l}0.859 \\
(7.207)\end{array}$ & $\begin{array}{l}2.281 \\
(6.445)\end{array}$ & $\begin{array}{l}-1.422 \\
(2.627)\end{array}$ & $\begin{array}{l}0.859 \\
(7.207)\end{array}$ & $\begin{array}{l}3.949 \\
(6.358)\end{array}$ & $\begin{array}{c}-3.090 \\
(2.395)\end{array}$ \\
\hline Regression & IV & IV & IV & IV & IV & IV \\
\hline Observations & 1015 & 1015 & 1015 & 1015 & 1015 & 1015 \\
\hline$R^{2}$ & 0.340 & 0.321 & 0.348 & 0.340 & 0.315 & 0.291 \\
\hline Fixed Effects & $p-f, g-f$ & $p-f, g-f$ & $p-f, g-f$ & $p-f, g-f$ & $p-f, g-f$ & $p-f, g-f$ \\
\hline AR test stat. & 2.695 & 2.255 & 1.363 & 2.695 & 0.964 & 8.618 \\
\hline KP test stat. & 40.59 & 40.59 & 40.59 & 40.59 & 40.59 & 40.59 \\
\hline DWH test stat. & 0.129 & 0.190 & 0.122 & 0.129 & 0.0682 & 0.140 \\
\hline
\end{tabular}

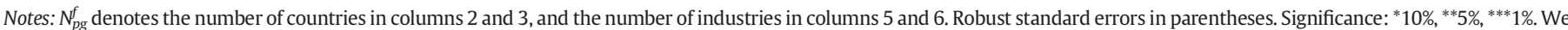
report Anderson-Rubin Wald test (AR test) and first-stage Kleibergen-Paap F-statistic (KP test).

consumer's valuation of time. They estimate an ad valorem tariff of 0.6$2.3 \%$ for each day in transit.

In our setting, one of the components of the domestic LPI (described in Section 2) is "export lead time," which measures the time it takes to transport goods from the point of origin to ports. The LPI data show that the median export lead time in Turkey decreased from 2.5 days in 2007 to 2 days in 2012, marking an improvement relative to the best performer (Singapore). Considering time as a trade cost, such evidence further motivates us to test the hypothesis that capacity-enhancing investment in road infrastructure in Turkey contributed relatively more to increased regional foreign trade in time-sensitive industries during the 2003-2012 period.

Heaviness is another determinant of how transportation intensive an industry is. Duranton et al. (forthcoming) estimate the effect of the US highway system on the value and composition of trade between US cities, and find that cities with more highways specialize in sectors producing heavy goods.

Guided by the empirical literature investigating the mode of shipping decisions, we define two industry-level variables, Air $_{i}$ and Heavy ${ }_{i}$, to capture characteristics that are related to transport intensity of goods:

$A i r_{i}=\frac{a i r_{-} v a l_{i}}{a i r_{\_} v a l_{i}+v e s_{\_} v a l_{i}} \quad, \quad$ Heavy $_{i}=\ln \left(\frac{\text { ves_wgt }_{i}}{\text { ves_val }_{i}}\right)$

where $a i r_{-} v a l_{i}$ denotes the value of trade by air for a country, and ves_val ${ }_{i}$ (ves_wgt $t_{i}$ ) the value (weight) of trade by ocean vessel. In order to capture industry characteristics in a setting that is exogenous to shipping decisions in Turkish trade, we use industry-level imports into the United

Table 9

Exports versus Imports.

\begin{tabular}{|c|c|c|c|c|c|}
\hline & (1) & $(2)$ & (3) & (4) & (5) \\
\hline & $\Delta \ln$ trade $_{p g}^{f}$ & $\Delta \ln$ trade $_{p g}^{f}$ & $\Delta \ln$ trade $_{p g}^{f}$ & $N e w_{p g}^{f}$ & $N e w_{p g}^{f}$ \\
\hline$\Delta R C_{p g}$ & $\begin{array}{l}1.308^{* *} \\
(0.571)\end{array}$ & $\begin{array}{l}0.973 \\
(0.712)\end{array}$ & $\begin{array}{l}1.643^{* *} \\
(0.770)\end{array}$ & $\begin{array}{l}0.228^{* * *} \\
(0.0748)\end{array}$ & $\begin{array}{c}-0.0146 \\
(0.0655)\end{array}$ \\
\hline$\Delta e r s_{p g}$ & $\begin{array}{c}-1.473 \\
(8.936)\end{array}$ & $\begin{array}{c}-5.113 \\
(11.61)\end{array}$ & $\begin{array}{l}2.168 \\
(11.30)\end{array}$ & $\begin{array}{l}2.400^{*} \\
(1.334)\end{array}$ & $\begin{array}{l}3.265^{* * *} \\
(1.183)\end{array}$ \\
\hline Regression & IV & IV & IV & IV & IV \\
\hline Observations & 754 & 377 & 377 & 1600 & 1600 \\
\hline$R^{2}$ & 0.242 & 0.426 & 0.369 & 0.110 & 0.0816 \\
\hline Flow & All & Export & Import & Export & Import \\
\hline Margin & Intensive & Intensive & Intensive & Extensive & Extensive \\
\hline Fixed Effects & p-f,g-f & $p-f, g-f$ & $p-f, g-f$ & $p-f, g-f$ & $p-f, g-f$ \\
\hline AR test stat. & 3.426 & 1.249 & 3.070 & 8.461 & 4.732 \\
\hline KP test stat. & 44.19 & 18.95 & 18.95 & 33.31 & 33.31 \\
\hline DWH test stat. & 0.116 & 0.116 & 2.630 & 6.006 & 2.744 \\
\hline
\end{tabular}

Notes: Robust standard errors in parentheses. Significance: ${ }^{*} 10 \%,{ }^{*}{ }^{*} 5 \%,{ }^{* * *} 1 \%$. We report Anderson-Rubin Wald test (AR test), first-stage Kleibergen-Paap F-statistic (KP test), and Durbin-Wu-Hausman F-statistic (DWH test).
Kingdom in 2005. Table 10 reports the values for both variables. As expected, the correlation coefficient between the two is strongly negative ( -0.54$)$-air shipping is less suitable for goods with a high weight-tovalue ratio (Harrigan, 2010). Beyond being of interest in and of itself, heaviness of an industry thus serves as an important control for air share to be a good proxy for time-sensitivity.

Our next specification interacts these variables with the change in road capacity:

$$
\begin{aligned}
\Delta \ln \text { trade }_{p g i}^{f}= & \delta_{p g}^{f}+\alpha \cdot \Delta R C_{p g} \times \theta_{i}+\gamma_{a} \cdot \Delta R C_{p g} \times \text { Air }_{i}+\gamma_{h} \cdot \Delta R C_{p g} \\
& \times \text { Heavy }_{i}+\epsilon_{p g i},
\end{aligned}
$$

where $\theta_{i}$ controls for potential differences in demand elasticities across industries. Here long-term differencing eliminates industry fixed effects

Table 10

\begin{tabular}{|c|c|c|c|c|}
\hline ISIC & Industry & Heavy $_{i}$ & $A i r_{i}$ & $\theta_{i}$ \\
\hline 15 & Food products and beverages & 1.340 & 0.082 & 4.563 \\
\hline 16 & Tobacco products & 0.300 & 0.065 & 10.472 \\
\hline 17 & Textiles & 0.375 & 0.165 & 4.357 \\
\hline 18 & Wearing apparel & 0.101 & 0.232 & 4.081 \\
\hline 19 & $\begin{array}{l}\text { Leather; manufacture of luggage, handbags, } \\
\text { footwear }\end{array}$ & 0.135 & 0.185 & 3.429 \\
\hline 20 & $\begin{array}{l}\text { Wood and of products of wood and cork, except } \\
\text { furniture }\end{array}$ & 1.320 & 0.018 & 2.650 \\
\hline 21 & Paper and paper products & 1.359 & 0.058 & 5.206 \\
\hline 22 & $\begin{array}{l}\text { Publishing, printing and reproduction of recorded } \\
\text { media }\end{array}$ & 0.257 & 0.327 & 2.302 \\
\hline 23 & Coke, refined petroleum products and nuclear fuel & 4.357 & 0.002 & 5.913 \\
\hline 24 & Chemicals and chemical products & 0.647 & 0.540 & 3.050 \\
\hline 25 & Rubber and plastics products & 0.457 & 0.119 & 3.245 \\
\hline 26 & Other non-metallic mineral products & 3.599 & 0.103 & 2.532 \\
\hline 27 & Basic metals & 0.783 & 0.073 & 3.016 \\
\hline 28 & $\begin{array}{l}\text { Fabricated metal products, except machinery and } \\
\text { equipment }\end{array}$ & 0.344 & 0.466 & 2.562 \\
\hline 29 & Machinery and equipment n.e.c. & 0.140 & 0.604 & 4.357 \\
\hline 30 & Office, accounting and computing machinery & 0.143 & 0.637 & 4.080 \\
\hline 31 & Electrical machinery and apparatus n.e.c. & 0.141 & 0.675 & 2.599 \\
\hline 32 & $\begin{array}{l}\text { Radio, television and communication equipment } \\
\text { and apparatus }\end{array}$ & 0.141 & 0.675 & 2.599 \\
\hline 33 & $\begin{array}{l}\text { Medical, precision and optical instruments, watches } \\
\text { and clocks }\end{array}$ & 0.063 & 0.777 & 2.863 \\
\hline 34 & Motor vehicles, trailers and semi-trailers & 0.205 & 0.117 & 3.868 \\
\hline 35 & Other transport equipment & 0.039 & 0.901 & 7.542 \\
\hline 36 & Furniture; manufacturing n.e.c. & 0.291 & 0.656 & 2.631 \\
\hline
\end{tabular}

Air shares, heaviness and demand elasticities of industries.

Notes: Air $_{i}$ and Heavy ${ }_{i}$ stand for air share and heaviness of industry-level imports into the UK in 2005. Precisely, air share is imports by air divided by total imports by air and vessel Heaviness is the natural logarithm of the weight/value ratio of imports by vessel. $\theta_{i}$ denotes the demand elasticity of industry $i$, estimated by Soderbery (2015) using Broda and Weinstein (2006) methodology. 
which may be driving air shares for reasons other than the timesensitivity of industries. If provinces with a higher increase in road capacity experienced a larger increase in the trade of time-sensitive and heavy goods, the coefficients $\gamma_{a}$ and $\gamma_{h}$ will be positive.

An important factor to consider in this exercise is that a systematic relationship between industries' demand elasticities and their heaviness/air shares will bias the estimates of $\gamma_{a}$ and $\gamma_{h}$. To address this concern, we control in Eq. (10) for the interaction between road capacity changes and industry-level elasticity of substitution $\theta_{i}$ estimated using the Broda and Weinstein (2006) methodology. ${ }^{24}$

Results are presented in Table 11. All specifications use the instrumental variable method and cluster standard errors at the provincegateway level. We also control for additional interactions such as $\Delta e r s_{p g} \times A i r_{i}$. To make coefficient interpretation easier, we redefine $A i r_{i}$ and $\operatorname{Heavy}_{i}$ as binary variables, indicating whether their values lie above their respective medians. Air share and heaviness have the expected signs and are significant at the $10 \%$ and $5 \%$ levels, respectively (column 1). Controlling for demand elasticities in the second column does not change the magnitude and significance of either variable, and we fail to find evidence that industries with higher elasticity benefited more from transport cost reductions.

In columns 3 and 4 of Table 11, we test whether fall in transport costs, caused by road capacity enhancements, increased the probability that $p g$ pairs start trading in transport-sensitive industries. To do so, we estimate an equation similar to Eq. (10) replacing the dependent variable with a binary variable that takes on the value one if a $p g$ pair trading in industry $i$ in the post-investment period did not do so in the preinvestment period, and zero otherwise. Since this equation is not estimated in differences, we also control for industry fixed effects. Results show that time sensitivity as captured by air shares matters for the initiation of trade in response to road quality improvements.

To understand the economic significance of our estimates, let us work through an example. Consider two routes at the 90th and 10th percentiles of expressway road share increase ( $\Delta$ ers). We ask how, at the median distance and for below-median heaviness, the trade responses of these two routes to a one percent increase in road capacity differ between two industries with above- and below-median air shares. Using the estimates from the first column of Table 11, we find an economically significant effect: the difference in trade increase is 50 percentage points. ${ }^{25}$

The stronger response in sectors that are expected to be more sensitive to road quality adds credibility to the claim that we are identifying the effect of reductions in transportation costs on trade. While we argued that endogenous selection is not a major concern in our setting, this claim is even stronger for the evidence presented here. It is very unlikely that planners prioritize investments in a province because of anticipated trade growth in certain products.

\section{Conclusion}

This study investigates the effect of Turkey's large-scale investment in the quality and capacity of its road transportation network on the level and composition of international trade associated with subnational regions within Turkey. Transport cost reductions brought about by this investment led to increased trade with regions whose connectivity to the international gateways of the country improved most, the main

\footnotetext{
24 In models that feature CES preferences, the elasticity of substitution governs the price elasticity of demand and trade elasticity (Arkolakis et al., 2012): a higher $\theta_{i}$ implies greater elasticity of trade to transport costs. We use elasticities at the HS10 level estimated by Soderbery (2015) and map it into our industry aggregation at the ISIC Rev.3 2 digit level. 25 Precisely, we calculate a double difference by evaluating the relative change in trade between industries with above- and below-median air shares for two routes with $\Delta e r s=0.27$ and $\Delta e r s=0.17$, corresponding to the 90th and 10th percentiles. Taking the median distance (dist $=775 \mathrm{~km}$ ) and Heavy $=0$, trade in an industry with abovemedian air-share doubles while trade in an industry with below-median air-share increases by $50 \%$.
}

Table 11

Transport intensity.

\begin{tabular}{|c|c|c|c|c|}
\hline & (1) & (2) & (3) & (4) \\
\hline & $\Delta \ln$ trade $_{p g i}^{f}$ & $\Delta \ln \operatorname{trade}_{p g i}^{f}$ & $N e w_{p g i}^{f}$ & $\mathrm{New}_{p g i}^{f}$ \\
\hline$\Delta R C_{p g} \times A i r_{i}$ & $\begin{array}{l}0.907^{*} \\
(0.481)\end{array}$ & $\begin{array}{l}0.884^{*} \\
(0.473)\end{array}$ & $\begin{array}{l}0.104^{* *} \\
(0.0491)\end{array}$ & $\begin{array}{l}0.0833^{*} \\
(0.0491)\end{array}$ \\
\hline$\Delta R C_{p g} \times$ Heavy $_{i}$ & $\begin{array}{l}1.129 * * \\
(0.541)\end{array}$ & $\begin{array}{l}1.113^{* *} \\
(0.555)\end{array}$ & $\begin{array}{l}0.0879 \\
(0.0581)\end{array}$ & $\begin{array}{l}0.0752 \\
(0.0583)\end{array}$ \\
\hline$\Delta e r s_{p g} \times A i r_{i}$ & $\begin{array}{l}-3.474 \\
(2.998)\end{array}$ & $\begin{array}{l}-3.579 \\
(2.949)\end{array}$ & $\begin{array}{l}-0.556 \\
(0.473)\end{array}$ & $\begin{array}{l}-0.480 \\
(0.474)\end{array}$ \\
\hline$\Delta e r s_{p g} \times$ Heavy $_{i}$ & $\begin{array}{l}-4.684 \\
(3.265)\end{array}$ & $\begin{array}{l}-4.740 \\
(3.351)\end{array}$ & $\begin{array}{l}-0.592 \\
(0.515)\end{array}$ & $\begin{array}{l}-0.559 \\
(0.519)\end{array}$ \\
\hline$\Delta R C_{p g} \times \theta_{i}$ & & $\begin{array}{l}-0.00275 \\
(0.215)\end{array}$ & & $\begin{array}{l}-0.0359^{* *} \\
(0.0170)\end{array}$ \\
\hline$\Delta e r s_{p g} \times \theta_{i}$ & & $\begin{array}{l}-0.376 \\
(1.292)\end{array}$ & & $\begin{array}{l}0.116 \\
(0.173)\end{array}$ \\
\hline Regression & IV & IV & IV & IV \\
\hline Observations & 5299 & 5299 & 12,203 & 12,203 \\
\hline$R^{2}$ & 0.008 & 0.009 & 0.056 & 0.056 \\
\hline Fixed Effects & p-g-f & $p-g-f$ & p-g-f,i & p-g-f,i \\
\hline AR test stat. & 5.764 & 4.284 & 2.429 & 2.404 \\
\hline KP test stat. & 150.5 & 83.64 & 17.18 & 11.68 \\
\hline DWH test stat. & 0.868 & 1.053 & 0.933 & 0.773 \\
\hline
\end{tabular}

Notes: Standard errors in parentheses are clustered at the pg level. Significance: * $10 \%,{ }^{*} 5 \%$, *** $1 \%$. New $w_{p g i}^{f}$ is equal to 1 if trade $_{p g i}^{f, 2012}>0$ and $\operatorname{trade}_{p g i}^{f, 2003}=0$, and zero otherwise. See text for further details.

channels being the increases in the extensive margins of industries and partner countries, as well as the intensive margin of average imports per province-gateway link. Our results thus support the idea that internal transportation infrastructure may play an important role in accessing international markets.

A particular channel for this regional response appears to be increased trade of transportation-intensive goods from regions that experienced the largest drop in transport costs. In particular, time-sensitivity of an industry matters for the effect of transport costs on the industrylevel trade. This is in line with the recent empirical literature emphasizing time costs in international trade. While existing studies typically emphasize time in transit between countries or time lost in customs, our results highlight the importance of domestic transportation infrastructure in moving goods from the factory gate to the ports in a timely and predictable fashion. To the extent that efficient logistics in timesensitive goods enable countries to take part in global supply chains and exploit their comparative advantages, our findings have important developmental implications.

Finally, note that this study focused on short-run effects by treating production locations as fixed. The aggregate trade response of an industry is a function of its initial location: if the supply of and demand for transport-intensive goods were initially agglomerated in provinces that had good market access to begin with, they would gain relatively little from transport cost reductions. ${ }^{26}$ Many economic geography models suggest that the direction of this change depends on the relative strength of agglomeration forces versus trade costs, making it hard to predict. This makes studying the long term impact of this large-scale infrastructure project on regional outcomes such as population, wages and welfare an interesting avenue for future research.

\section{Appendix A. Supplementary data}

Supplementary data to this article can be found online at http://dx. doi.org/10.1016/j.jdeveco.2015.10.001.

\footnotetext{
${ }^{26}$ The possibility of such selection should not cause any bias in our estimates as we are using long-term differences-which eliminate any time-invariant province-industry factors such as location. Thus, the long term effect of the infrastructure investment could be more drastic if transport intensive industries endogenously locate towards the now better-connected interior of the country.
} 


\section{References}

ADBI, 2009. Infrastructure for a Seamless Asia. Discussion paper. Asian Development Bank Institute, Tokyo.

Albarran, P., Carrasco, R., Holl, A., 2013. Domestic transport infrastructure and firms export market participation. Small Bus. Econ. 40 (4), 879-898.

Allen, T., Arkolakis, C., 2014. Trade and the topography of the spatial economy. Q. J. Econ. 129 (3), 1085-1140.

Amiti, M., Konings, J., 2007. Trade liberalization, intermediate inputs, and productivity: evidence from Indonesia. Am. Econ. Rev. 97 (5), 1611-1638.

Anderson, J.E., van Wincoop, E., 2004. Trade costs. J. Econ. Lit. 42 (3), 691-751.

Arkolakis, C., Costinot, A., Rodriguez-Clare, A., 2012. New trade models, same old gains? Am. Econ. Rev. 102 (1), 94-130.

Atkin, D., and D. Donaldson (2014): "Who's Getting Globalized? The Size and Nature of Intranational Trade Costs," UCLA mimeo.

Broda, C., Weinstein, D.E., 2006. Globalization and the gains from variety. Q. J. Econ. $541-585$.

Conley, T.G., Hansen, C.B., Rossi, P.E., 2012. Plausibly exogenous. Rev. Econ. Stat. 94 (1), 260-272.

Coşar, A.K., Fajgelbaum, P., 2014. Internal geography, international trade, and regional specialization. Am. Econ. J. Microecon. (forthcoming).

Demir, B., 2011. Transport costs and Turkey's international trade. Background Paper for Turkey Transport Sector Expenditure Review (2012).

Donaldson, D., 2012. Railroads of the Raj: estimating the impact of transportation infrastructure. NBER Working Paper No. w16487.

Donaldson, D., Hornbeck, R., 2013. Railroads and American economic growth: a market access approach. NBER Working Paper No. w19213.

Duranton, G., Morrow, P., Turner, M.A., 2013. Roads and trade: evidence from the US. Rev. Econ. Stud. (forthcoming).

Evans, C.L., Harrigan, J., 2005. Distance, time, and specialization: lean retailing in general equilibrium. Am. Econ. Rev. 292-313.

GDH, 2012. Turkish General Directorate Of Highways, Highway Transportation Statistics Website http://www.kgm.gov.tr/SiteCollectionDocuments/KGMdocuments/Yayinlar/ YayinPdf/KarayoluUlasimIstatistikleri2012.pdf.

GDH, 2014. Turkish general directorate of highways, divided highway projects Website http://translate.google.com/translate?hl=en $\mathrm{sl}=\mathrm{tr} \mathrm{tl}=\mathrm{en} \mathrm{u}=\mathrm{http}$ ://www.kgm.gov. tr/Sayfalar/KGM/SiteTr/Projeler/Projeler-BolunmusYol.aspx.

Goldberg, P.K., Pavcnik, N., 2005. Trade, wages, and the political economy of trade protection: evidence from the Colombian trade reforms. J. Int. Econ. 66 (1), 75-105.

Harrigan, J., 2010. Airplanes and comparative advantage. J. Int. Econ. 82 (2), 181-194.

Head, K., Mayer, T., 2014. Chapter 3 - gravity equations: workhorse,toolkit, and cookbook. In: Elhanan Helpman, K.R., Gopinath, G. (Eds.), Handbook of International EconomicsHandbook of International Economics vol. 4. Elsevier, pp. 131-195.
Hirano, K., Imbens, G.W., 2004. The propensity score with continuous treatments. In: Gelman, A., Meng, X.-L. (Eds.), Applied Bayesian Modeling and Causal Inference from Incomplete-Data Perspectives. Wiley.

Hummels, D., Schaur, G., 2013. Time as a trade barrier. Am. Econ. Rev. 103 (7), 2935-2959.

IADB, 2013. Too far to export: domestic transport costs and regional export disparities in Latin America and the Caribbean. Discussion paper. Inter-American Development Bank, Washington, DC

Limao, N., Venables, A.J., 2001. Infrastructure, geographical disadvantage, transport costs, and trade. World Bank Econ. Rev. 15 (3), 451-479.

Mulligan, C.B., Rubinstein, Y., 2008. Selection, investment, and women's relative wages over time. Q. J. Econ. 123 (3), 1061-1110.

Nunn, N., Wantchekon, L., 2011. The slave trade and the origins of mistrust in Africa. Am. Econ. Rev. 101 (7), 3221-3252.

Redding, S., Venables, A.J., 2004. Economic geography and international inequality. J. Int. Econ. 62 (1), 53-82.

Rousslang, D.J., To, T., 1993. Domestic trade and transportation costs as barriers to international trade. Can. J. Econ. 208-221.

Santos-Silva, J.M.C., Tenreyro, S., 2006. The log of gravity. Rev. Econ. Stat. 88 (4), 641-658.

Simonovska, I., Waugh, M., 2014. The elasticity of trade: estimates and evidence. J. Int. Econ. 92 (1), 34-50.

Soderbery, A., 2015. Estimating import supply and demand elasticities: analysis and implications. J. Int. Econ. 96 (1), 1-17.

Topalova, P., 2010. Factor immobility and regional impacts of trade liberalization: evidence on poverty from India. Am. Econ. J. Appl. Econ. 2 (4), 1-41.

Volpe Martincus, C., Blyde, J., 2013. Shaky roads and trembling exports: assessing the trade effects of domestic infrastructure using a natural experiment. J. Int. Econ. 90 (1), 148-161.

Volpe Martincus, C. J. Carballo, and A. Cusolito (2013): "Routes, exports and employment in developing countries: following the trace of the inca roads," Inter-American Development Bank, mimeo.

WB, 2009. World development report: reshaping economic geography. Discussion paper. World Bank, Washington, DC

WTO, 2004. World Trade Report 2004: exploring the linkage between the domestic policy environment and international trade. Report WTO/WTR/2004. World Trade Organization (WTO), Geneva.

Yeaple, S., Golub, S., 2007. International productivity differences, infrastructure, and comparative advantage. Rev. Int. Econ. 15 (2), 223-242. 